Cahiers Charlevoix

Études franco-ontariennes
Cahiers Charlevoix Études franco-ontariennes

or Crevenerix of

\title{
Disparités socio-économiques et culturelles à Ottawa en 1871
}

\section{Fernand Ouellet}

Volume 6, 2005

URI : https://id.erudit.org/iderudit/1039331ar

DOI : https://doi.org/10.7202/1039331ar

Aller au sommaire du numéro

\section{Éditeur(s)}

Société Charlevoix

Presses de l'Université d'Ottawa

ISSN

1203-4371 (imprimé)

2371-6878 (numérique)

Découvrir la revue

Citer cet article

Ouellet, F. (2005). Disparités socio-économiques et culturelles à Ottawa en 1871 Cahiers Charlevoix, 6, 15-97. https://doi.org/10.7202/1039331ar

\section{Résumé de l'article}

Fernand Ouellet dirige son attention vers la région d'Ottawa. Considérant les diverses communautés ethniques en présence selon des points de vue éprouvés (origine géographique et ethnique, religion, alphabétisation, moment d'arrivée, territorialité, etc.) et qui ont hiérarchisé ces groupes, Ouellet retrouve et confirme les " disparités socio-économiques et culturelles » qu'il avait antérieurement observées. Il montre ainsi que le succès des établissements homogènes canadiens-français aux chapitres religieux et linguistique était assorti d'aspects négatifs formant des barrières à l'amélioration de leurs conditions socio-économiques : un taux élevé d'analphabétisme lié à l'infériorité sociale qui en découlait. Il fait voir en outre que la minorité anglo-protestante (Anglais, Écossais, Allemands et Irlandais), qui dominait alors la vie économique et sociale d'Ottawa, distançait largement la majorité catholique et que, parmi celle-ci, les Irlandais, à leur tour, devançaient les Canadiens français ; les rivalités entre ces deux communautés se logèrent donc à un autre niveau puisqu'elles se disputaient les emplois subalternes et le pouvoir à l'intérieur de l'Église. Selon l'auteur, les appuis politiques des Canadiens français et l'énorme pouvoir de l'Église du Québec jouèrent abondamment en leur faveur au détriment du groupe irlandais catholique. 


\title{
DISPARITÉS SOCIO-ÉCONOMIQUES ET CULTURELLES À OTTAWA EN 1871*
}

\author{
Fernand Ouellet
}

Département d'histoire

Université York, Toronto

* Ce texte a été rédigé grâce à l'appui du programme Killam.

Cahiers Charlevoix 6, 2004, p. 15-97 


\section{SOMMAIRE}

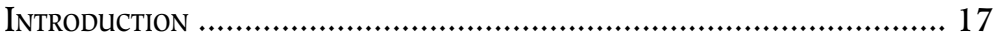

I - ORIGINe GÉOGRAPHIQUe ET ETHNIQUE DE LA POPULATION

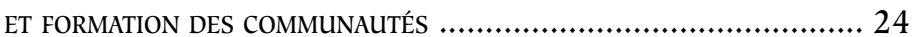

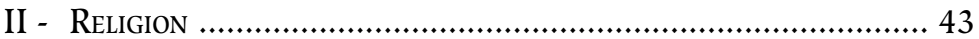

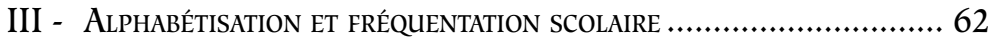

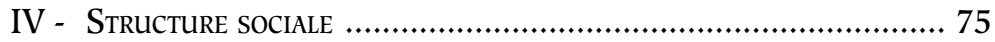

A. La dynamique de la constitution du revenu familial ....... 76

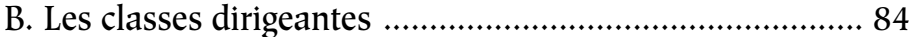

C. Une section du prolétariat : les journaliers,

les hommes de chantier et les voyageurs .......................... 90






\section{DISPARITÉS SOCIO-ÉCONOMIQUES ET CULTURELles À OtTAWA EN 1871}

\section{INTRODUCTION}

Jusqu'en 1826, Ottawa, souvent connu sous le nom de Les Chaudières, n'avait guère été qu'un lieu de transbordement inhabité sur la route de l'Outaouais: à l'aller, pour les marchandises de traite vers les Grands Lacs et, au retour, pour les pelleteries vers Montréal et Québec. Pourtant, depuis la fin du XVIII siècle, grâce surtout à l'immigration venue des îles Britanniques et du Canada-Est, des communautés ethniques s'étaient formées dans l'Est ontarien, la colonisation agricole avait progressé, ainsi que l'économie forestière. Dans le comté de Carleton, plusieurs agglomérations rurales, dont celle de Nepean, avaient pris forme sous l'égide d'une "gentility» recrutée parmi des officiers militaires et des marchands richement dotés de terres ${ }^{1}$. Mais tout cela n'avait pas suffi à animer le site, pourtant avantageux, des Chaudières.

L'éclosion presque subite d'une ville en ces lieux devait beaucoup plus aux craintes qu'inspirait toujours, vers 1820 , pour la sécurité du Haut-Canada, le souvenir de l'invasion américaine de 1812 qu'à tout autre motif. L'idée d'ériger

\footnotetext{
${ }^{1}$ Michael Cross, «The Age of Gentility. The Formation of an Aristocrracy in the Ottawa Valley», Historical Papers, 1967, p. 105-128.
} 
une ligne de canaux sur le Saint-Laurent, émise au début du siècle, se justifiait d'abord par des considérations exclusivement économiques, alors que celle qui vint plus tard de construire un canal reliant Kingston aux Chaudières répondait plutôt à des préoccupations militaires et stratégiques. De là, la décision prise en 1826 de confier l'entreprise Rideau au colonel John By ${ }^{2}$ qui la compléta en 1832. L'année 1826 marquait ainsi le début du peuplement d'Ottawa et de sa vocation urbaine. La division du sol entre plusieurs grands propriétaires, dont Nicholas Sparks, le colonel John By, Louis Besserer, Thomas McKay et l'Ordonnance, marquait l'entrée en scène rapide des intérêts fonciers, suivie de celle des travailleurs et des fournisseurs du canal, qui exercèrent des pressions pour avoir accès à des emplacements à titre de locataires ou de propriétaires. Dès le printemps 1827, Les Chaudières reçurent le nom de Bytown ${ }^{3}$. L'année suivante, sa population se chiffrait à environ 1000 individus. Puis, avant et après la fin des travaux de la construction du canal, sa croissance resta, jusqu'en 1850, sujette à de fortes variations attribuables à la fin des travaux et aux fluctuations économiques. C'est donc dire que, pendant assez longtemps, il y eut une substantielle population flottante et, plus qu'ailleurs, des pouvoirs publics désorganisés. Il va de soi que le canal Rideau n'a jamais joué le rôle stratégique que ses concepteurs lui avaient attribué. Par contre, il serait exagéré de prétendre que sa fonction économique fut nulle,

\footnotetext{
${ }^{2}$ George Raudzens, The British Ordnance Department and Canada's Canals, 1815-1855, Waterloo, Wilfrid Laurier University Press, 1979, p. 40-99. «After centuries of Growth, by mid-1820s it had become a body with substantial administrative autonomy. Staffed by both soldiers and civilians, it controlled all military property, arms, equipment, and fortification work, and supplied both the armed forces and civilian departments of state with a wide range of engineering, technical and scientific services", p. IX.

${ }^{3}$ John Taylor, Ottawa. An Illustrated History, Toronto, James Lorimer and Canadian Museum of Civilization, 1986, p. 14; Lucien Brault, Ottawa, Old and New, Otttawa Historical Information Institute, 1946, p. 18.
} 
comme le prétend Gerald Craig . Le volume du trafic sur le canal dans les deux directions, entre 1833 et 1839, sans être comparable à celui des canaux du Saint-Laurent, était loin d'être insignifiant. En 1836, 785 bâtiments de toutes sortes franchirent les écluses ${ }^{5}$ en remontant le Rideau. Cela stimula aussi le peuplement et la marche de l'agroforesterie aussi bien au sud-ouest de la ville qu'à l'ouest.

La construction du canal aura permis de lier progressivement le destin de la ville à celui de l'économie forestière qui se pratiquait sur l'Outaouais, à l'agriculture régionale et, plus généralement, au trafic qui animait le SaintLaurent à l'ouest de Montréal. L'expansion de l'industrie du bois de construction dans les limites de la ville, associée qu'elle était à la montée de la demande dans les villes américaines, apparaît alors comme un événement économique et social majeur. Cela explique, en partie, que, dès 1860, la ville de Bytown, devenue Ottawa quelques années plus tôt, aura surclassé, au moins sur le plan démographique, Kingston, dont les effectifs augmentèrent à peine, entre 1851 et 1871 , alors que la population d'Ottawa tripla presque pendant la même période. Quant au choix, en 1857, d'Ottawa comme capitale nationale, il s'agissait d'un autre événement majeur dont les répercussions lointaines furent encore plus considérables pour l'avenir de la cité que la construction du canal Rideau. Mais, dans l'immédiat, ce furent surtout les dépenses consenties pour l'aménagement des édifices parlementaires qui eurent un effet stimulant. À plus long terme, c'est-à-dire après 1866, ce fut la présence des députés, des ministres et des employés de l'État qui influa de plus en plus et d'une façon décisive sur le développement et le caractère d'une ville qui avait connu

\footnotetext{
${ }^{4}$ Gerald M. Craig, Upper Canada. The Formative Years, 1784-1841, Toronto, McClelland and Stewart, 1963, p. 153.

${ }^{5}$ APC, RG I, Report on Inland Navigation (Rideau Canal), 1832-1839.
} 
l'agitation et l'instabilité. Ville que, peu après son arrivée d'Europe en 1842, le curé A. Neyron avait qualifié de "petite Babylone ${ }^{6}$ ".

En plus d'être ainsi connectée à ce qui se passait dans l'ensemble du pays, la ville d'Ottawa l'était par les demandes variées de capitaux, de main-d'œuvre et d'institutions qu'elle faisait à l'Est ontarien rural, au Québec urbain et rural, à l'Europe et au marché américain. Sa main-d'œuvre de toutes catégories provenait, directement ou par étapes, de ces régions. Elle était donc multiculturelle et multiconfessionnelle, comme l'était la population de l'Est ontarien. Non seulement était-elle la métropole de l'Est ontarien, mais son rôle à cet égard ne fait que s'accroître en raison de ses liens avec Montréal. Dans la région, la proportion des Canadiens français s'était accrue de 4,8\% en 1851 à $10,5 \%$ en 1871 . Dans Ottawa, ce pourcentage passa de $26,7 \%$ à $36,7 \%$.

C'est dans ce contexte qu'Ottawa, ville fortement tributaire de Montréal, contribua et bénéficia du processus d'urbanisation qui, pour de bon, se précisa davantage en Ontario vers $1850^{7}$. Fait à noter, la population urbaine canadienne-française de l'Est ontarien était concentrée à Ottawa dans une proportion de plus de $70 \%$ en 1850 , de $56 \%$ en 1871 et de $44 \%$ en 1911 . Au contraire, avant 1871 , moins de $20 \%$ des anglophones urbains y étaient rassemblés; quarante ans plus tard, ce pourcentage s'était élevé à $30 \%$. Ce sont donc les demandes de produits agricoles et forestiers canadiens sur les marchés internationaux et locaux, l'abondance des terres en Ontario, facteur d'attraction pour les immigrants, qui rendent le

\footnotetext{
${ }^{6}$ Cité dans Robert Choquette, L'Église catholique dans l'Ontario français du dix-neuvième siècle, Ottawa, les PUO, 1984, p. 70.

${ }^{7}$ Fernand Ouellet, "Canadiens français et non-francophones dans les villes québécoises et ontariennes, 1851-1911: une perspective comparative et régionale », J. Cotnam, Y. Frenette, A. Whitfield (dir.), La Francophonie ontarienne: bilan et perspectives de recherche, Ottawa, Le Nordir, 1995, p. 142, 159.
} 
mieux compte, autant que les considérations militaires et politiques, du cheminement d'Ottawa de 1850 à 1871.

Afin de mieux saisir cette complexité et la dynamique qui anima les rapports entre Ottawa et sa région entre 1851 et 1871 , nous avons préparé le tableau 1 qui fait état des occupations déclarées par les individus dans l'Est ontarien. La ville d'Ottawa y figure, ainsi que deux autres types de comtés.

\section{TABLEAU 1}

Ottawa et l'Est ontarien en 1851 et en 1871 . Structure et répartition des occupations déclarées* selon la nature des comtés: (1) Ottawa,

(2) comtés avec villes et villages, (3) comtés entièrement ruraux.

\begin{tabular}{|c|c|c|c|c|c|c|c|c|}
\hline \multirow[b]{3}{*}{$\begin{array}{l}\text { Recensement de } 1851 \\
\text { population }\end{array}$} & \multicolumn{2}{|c|}{ Ottawa } & \multicolumn{2}{|c|}{$\begin{array}{c}\text { Comtés avec } \\
\text { villes et villages }\end{array}$} & \multicolumn{2}{|c|}{$\begin{array}{l}\text { Comtés } \\
\text { entièrement } \\
\text { ruraux }\end{array}$} & \multirow{2}{*}{$\begin{array}{r}\text { Total } \\
\text { nombre }\end{array}$} & \multirow[b]{2}{*}{$\%$} \\
\hline & nombre & $\%$ & nombre & $\%$ & nombre & $\%$ & & \\
\hline & 7760 & 2,7 & 180240 & 63,4 & 96449 & 33,9 & 284449 & 100 \\
\hline $\begin{array}{l}\text { Occupations déclarées } \\
\text { professions et affaires }\end{array}$ & 200 & 5,7 & 2433 & 69,3 & 877 & 25,0 & 3510 & 100 \\
\hline artisans & 752 & 6,2 & 2152 & 17,9 & 9134 & 75,9 & 12038 & 100 \\
\hline journaliers & 1115 & 3,8 & 17541 & 59,9 & 10643 & 36,3 & 29299 & 100 \\
\hline cultivateurs & 40 & & 15712 & 61,8 & 9683 & 38,1 & 25435 & 99,9 \\
\hline divers & 40 & 1,4 & 572 & 75,4 & 148 & 23,2 & 760 & 100 \\
\hline total & 2147 & 3,0 & 38410 & 54,0 & 30485 & 43,0 & 71042 & 100 \\
\hline $\begin{array}{l}\text { Recensement de } 1871 \\
\text { population }\end{array}$ & 21545 & 5,5 & 332397 & 84,9 & 32397 & 9,6 & 391337 & 100 \\
\hline $\begin{array}{l}\text { Occupations déclarées } \\
\text { professions et affaires }\end{array}$ & 1457 & 14,9 & 7873 & 80,6 & 439 & 4,5 & 9769 & 100 \\
\hline artisans & 2427 & 12,6 & 15863 & 82,6 & 901 & 4,7 & 19191 & 99,9 \\
\hline journaliers & 2699 & 13,0 & 16641 & 80,2 & 1403 & 6,8 & 20743 & 100 \\
\hline cultivateurs & 14 & & 50363 & 90,2 & 5423 & 9,7 & 55800 & 100 \\
\hline divers & 125 & 4,4 & 2702 & 94,5 & 32 & 1,1 & 2859 & 100 \\
\hline total & 7117 & 6,6 & 93029 & 85,8 & 8216 & 7,6 & 108362 & 100 \\
\hline
\end{tabular}

Sources: APC, Recensements publiés du Canada de 1851 et de 1871.

* Les recensements de 1851 et 1861 posent un problème puisque, sur l'ordre des autorités, les recenseurs de ces années avaient inscrit les fils de cultivateurs qui vivaient à la maison et se disaient eux-mêmes cultivateurs, 
parmi les journaliers. Cette décision avait contribué à gonfler le groupe des journaliers et, par le fait même, avait aminci celui des cultivateurs. Il faut dire qu'ils n'avaient pas eu entièrement tort puisqu'un grand nombre de ces adultes, surtout ceux appartenant aux unités moins productives, participaient aussi à des travaux saisonniers, soit sur d'autres fermes, soit dans les chantiers de l'Outaouais. Au contraire, en 1871, ces individus qui se déclaraient cultivateurs avaient été inscrits selon leur propre déclaration.

Même si le recensement de 1851 exagère le nombre de journaliers par rapport au nombre de cultivateurs, les chiffres, tels que regroupés, reflètent d'une façon adéquate la marche du processus d'urbanisation dans l'est de la province. Ainsi, en 1851, il y avait huit comtés sur dix-sept qui étaient entièrement ruraux. Le tiers de la population et $43 \%$ des personnes qui avaient déclaré des occupations y étaient concentrés. Vingt ans plus tard, le nombre des comtés complètement ruraux avait chuté à deux. Moins de $10 \%$ de la population et seulement $8 \%$ des personnes qui avaient déclaré des occupations y résidaient. Pendant ce temps, le poids d'Ottawa dans la région, bien que modeste, n'avait cessé d'augmenter ${ }^{8}$.

En somme, il s'agissait d'une ville en plein mouvement, dont la population avait presque triplé en vingt ans. L'image que nous en dégageons le plus fidèlement possible provient du recensement nominatif de $1871^{9}$. Même si certaines pages du document ont été perdues, nos chiffres diffèrent un peu de ceux qui apparaissent dans le recensement publié. Ainsi, nos données relatives à la population totale sont de 3,6\% inférieures à celles du recensement publié, alors que celles relatives à la population catholique le sont par une marge de $4,1 \%$, ce qui ne peut aucunement affecter la validité de nos conclusions. Ceci dit, notre analyse des personnes adultes repose d'abord sur 3937 chefs

\footnotetext{
${ }^{8}$ Pour une analyse de l'historiographie, voir R. W. Sandwell, «Rural Reconstruction. Towards a New Synthesis in Canadian History", HS/SH, vol. 27, 1994, p. 1-32; Fernand Ouellet, «Développement et sous-développement en milieu colonial pré-industriel», Acadiensis, 22, 1992, p. 146-168.

${ }^{9}$ APC, recensement nominatif de 1871, bobines 10 013, 10 014, 10015 .
} 
de maisonnée, dont 1419 Irlandais, 36 Allemands, 744 Anglais, 396 Écossais et 1342 Canadiens français. Viennent ensuite 5885 personnes, également diverses par l'ethnicité, dont 3258 épouses, suivies de 982 adultes, membres de la famille et vivant avec elle, mais non chefs de maisonnée, de 797 étrangers à la famille, non chefs de maisonnée, bien qu'y résidant, et, finalement, de 848 servantes et serviteurs.

En 1871, Ottawa était devenue relativement paisible en apparence. Mais ses habitants avaient-ils, pour autant, réglé leurs comptes avec le passé, notamment celui entre les Irlandais catholiques et les Canadiens français? Nous pouvons d'autant plus en douter que ces deux groupes les plus pauvres et les moins instruits, en compétition les uns avec les autres, étaient concentrés, à l'est dans les quartiers Ottawa et By, et, à l'ouest dans la section 2 de Victoria, et que les plus riches et les plus influents l'étaient à la haute ville. Les Canadiens français dominaient numériquement à la basse ville: $94 \%$ d'entre eux et $52 \%$ des Irlandais y étaient regroupés. C'est là aussi que résidaient $80 \%$ des catholiques et $64 \%$ des Irlandais catholiques. En 1848, $M^{\text {gr }}$ Guigues, premier évêque d'Ottawa, disait:

Les catholiques généralement parlant sont moins riches et il faut nous dire qu'ils sont moins soucieux que les protestants pour soutenir leurs droits. Ils ne comptent que deux membres dans la corporation [urbaine] et deux dans les comités des écoles tandis qu'ils devraient se trouver partout en majorité ${ }^{10}$.

C'est cette distance entre les riches et les pauvres que nous voulons départager par étapes et par touches, sans pour autant nous engager dans une étude quantitative des revenus et des salaires. Notre démarche consiste plutôt à extraire, à mesure que progresse notre analyse, les indicateurs de statut et de fortune. D'abord, dans les groupes

\footnotetext{
${ }^{10}$ Cité dans Robert Choquette, L'Église catholique dans l'Ontario français du dix-neuvième siècle, Ottawa, PUO, 1984, p. 140. En 1848, le pourcentage de la population catholique se chiffrait à $62 \%$.
} 
ethniques: leur profil, leur territorialité, leurs composantes sociales, et, ensuite, leurs différences à ces égards quant au moment de l'arrivée dans la ville, à la religion, à l'éducation, à l'économie et à leur rang dans la hiérarchie sociale.

\section{I - Origine géographique et ETHNiQUe de LA POPULATION ET FORMATION DES COMMUNAUTÉS}

Le peuplement d'Ottawa, comme la création de toutes pièces, trente ans plus tôt, des villes d'Amherstburg et de Sandwich (Essex), s'était engagé presque subitement en 1826 , donc, bien après celui des campagnes environnantes. En 1871, les chefs de maisonnée de la ville étaient plus jeunes que ceux des cantons ruraux de Hawkesbury et d'Alfred: les anglophones de 5,4 ans en moyenne et les Canadiens français de 3,2 ans. Comme ce mouvement avait aussi bénéficié, quoique plus tardivement, des migrations internationales, régionales et locales, la proportion des individus nés en Ontario y était beaucoup plus faible encore que dans ces cantons ruraux: dans le cas des anglophones, 16,2\% à Ottawa contre $47,7 \%$ à Hawkesbury et à Alfred et, dans celui des Canadiens français, 6,8\% contre $14,4 \%$. Tout cela reflète à la fois le caractère récent de l'enracinement urbain et le fait qu'aux trois endroits les Canadiens français étaient arrivés à la suite des Écossais, des Irlandais et des autres. 
DisPARITÉS SOCIO-ÉCONOMIQUES ET CULTURELLES À OTTAWA EN 1871

TABLEAU 2

Chefs de maisonnée selon leur âge, leur origine ethnique

et géographique et leurs années de résidence à Ottawa en 1871.

\begin{tabular}{|c|c|c|c|c|c|c|c|}
\hline & Écossais & Anglais & $\begin{array}{l}\text { Alle- } \\
\text { mands }\end{array}$ & Irlandais & $\begin{array}{l}\text { Anglo- } \\
\text { phones }\end{array}$ & $\begin{array}{c}\text { Canadiens } \\
\text { français }\end{array}$ & Total \\
\hline Nombre & 396 & 744 & 36 & 1419 & 2595 & 1342 & 3937 \\
\hline âge moyen & 41,6 & 41,0 & 40,8 & 43,3 & 42,3 & 39,2 & 41,3 \\
\hline résidence (années) & 16,1 & 11,7 & 14,4 & 14,3 & 13,9 & 9,1 & 12,2 \\
\hline \multicolumn{8}{|l|}{ Nés en Ontario } \\
\hline$\%$ & 21,7 & 13,8 & 25,0 & 15,6 & 16,2 & 6,8 & 13,0 \\
\hline âge moye & 35,5 & 33,5 & 42,4 & 33,4 & 34,0 & 29,4 & 33,2 \\
\hline années de résidence & 35,5 & 33,5 & 42,4 & 33,4 & 34,0 & 29,4 & 33,2 \\
\hline \multicolumn{8}{|l|}{ Nés ailleurs } \\
\hline nombre & 310 & 641 & 27 & 1197 & 2175 & 1250 & 3425 \\
\hline$\%$ & 78,3 & 86,2 & 75,0 & 84,4 & 83,8 & 93,2 & 87,0 \\
\hline âge & 43,4 & 42,3 & 40,3 & 45,1 & 44,0 & 39,9 & 42,4 \\
\hline années de résidence & 10,8 & 8,2 & 5,1 & 10,8 & 10,0 & 7,6 & 9,1 \\
\hline
\end{tabular}

Sources: APC, Recensement nominatif d'Ottawa de 1871, bobines 10013 , 10014 et 10015 .

Ainsi, $84 \%$ des chefs de maisonnée anglophones n'étaient dans la province que depuis une quinzaine d'années et $93 \%$ des francophones n'y étaient que depuis dix ans en moyenne. Même si bien des choses avaient changé en trente ans, le passé instable et troublé de la ville, maintenant si fortement intégrée dans l'économie forestière de la vallée, n'avait pas été chassé entièrement de la mémoire de ses habitants. D'autant plus que sa population était rigidement structurée sur le plan ethnique et, encore, polarisée entre les Irlandais, qui la dominaient numériquement, et les Canadiens français, maintenant bien ancrés dans les emplois forestiers aussi bien dans la ville que dans la vallée. En 1843, au cours de son voyage de Montréal vers l'Outaouais supérieur, le père Dominique du Ranquet avait inscrit dans son journal:

C'est toujours et plus que jamais à Bytown que se rassemble la jeunesse du Bas-Canada, des environs de Montréal surtout, pour 
prendre du service dans les chantiers [...]. Bytown, cette ville qui a paru tout à coup dans le désert, a été plus d'une fois le théâtre du désordre et de la violence qui doivent toujours suivre des réunions ainsi formées $[\ldots]^{11}$.

Et, en 1875 , le père Henri Tabaret, parlant des rapports entre les religieux eux-mêmes, écrivait :

les Canadiens [français] ne voient de bon que ce qui se fait dans le Bas-Canada. Les Irlandais au contraire n'estiment que ce qui est anglais et fait par eux. Notre nationalité, notre ignorance de l'anglais, notre titre de religieux, autant de raisons qui nous empêchent d'avoir l'influence que nous devrions avoir dans la société d'Ottawa $[\ldots]^{12}$.

Les confrontations épiques des années 1830, connues sous le nom de Shiners' War, dont le souvenir s'était perpétué par les récits à caractère légendaire de ces combats entre Irlandais et Canadiens français, ont, plus tard, donné lieu à une historiographie qui prétendait simplement replacer ces événements dans leur contexte. Ainsi, selon Cross, les Irlandais auraient alors constitué à Bytown un groupe numériquement marginal, socialement rejeté et, pour cette raison, devenu menaçant. Dans son analyse, Cross ${ }^{13}$ commence, dans un premier temps, par attirer l'attention, avec raison, sur la faiblesse des pouvoirs publics et des institutions ecclésiastiques de l'époque. Puis, dans un second temps, il incrimine les Irlandais directement impliqués dans ces conflits, mettant alors en cause leur passé de violence, leurs mauvaises habitudes de vie, leur bas niveau social et leur analphabétisme: "for savagery

\footnotetext{
${ }^{11}$ Fernand Ouellet et René Dionne (dir.), Journal du père Dominique du Ranquet, missionnaire jésuite en Ontario de 1843 à 1900, de la mission qu'il fit en 1843 dans l'Outaouais supérieur sous la direction de l'abbé Hyppolite Moreau, Ottawa, Vermillon, 2000, p. $81 \mathrm{~s}$.

${ }_{12}$ Cité dans Roger Guindon, Coexistence difficile. La dualité linguistique à l'Université d'Ottawa, 1848-1898, vol. I, Ottawa, PUO, 1989, p. 55.

${ }^{13}$ Michael Cross, "The Shiners' War: Social Violence in the Ottawa Valley in the 1830 s", CHR, 54, 1973, p. 1-26. Pour une analyse plus complexe de ces événements vus de la vallée et non de la ville, voir aussi Chad Gaffield (dir.), Histoire de l'Outaouais, p. 210-220.
} 
and intimidation, dit-il, the French Canadians could not match the Shiners ». Enfin, dans un troisième temps, il procède à la réhabilitation de ces mêmes individus, «lacking skills and experience ", qui tentaient de briser le monopole des emplois forestiers détenus par les Canadiens français, aussi bien dans la ville que dans la vallée. Ainsi décorés, les Shiners pouvaient désormais faire figure d'avant-garde victimisée et tumultueuse dont la lutte symbolisait le besoin d'intégration de tous les Irlandais dans la société. Sur ce point, Cross écrit:

The community of Bytown and Carleton County failed to absorb the Irish and to give them a legitimate place within that community. They were denied economic security; they were the last hired and first fired [...]. The Shiners [...] transformed society's attitude towards violence more rapidly than would otherwise have been the case. For they committed a major crime: they did not accept the comic role cast for them, the role of drunken browling Paddy. Instead, faced by a society which would make no room for them, they attempted to use their force to coerce that society into opening itself to them. But the times of the lower orders had not yet come ${ }^{14}$.

Pourtant, s'il était démontré que la suprématie numérique, dont les Irlandais jouissaient en 1871, avait existé de tout temps à Bytown et que ceux-ci étaient bien représentés à tous les niveaux de l'échelle sociale, ne serionsnous pas en droit de ne retenir de ce brillant et dramatique discours, si souvent repris par d'autres, qu'une autre contribution aux légendes érigées, d'une part, autour de Peter Aylen, personnage plus que douteux, mais glorifié par les siens, et de l'imbattable Jos Montferrand, champion des intérêts canadiens-français?

Pour tester ce discours sur les affrontements ethniques et les classes sociales originelles, nous avons tenté de reconstituer, décennie par décennie, la composition ethnique de la ville à partir des individus habitant Ottawa en 1871, ne

${ }^{14}$ Ibid., p. 26. 
retenant parmi eux, que ceux nés en Ontario de parents qui avaient été des immigrants ${ }^{15}$. Il s'agit des chefs de maisonnée, des épouses et des autres adultes résidant dans la maisonnée et ayant déclaré des occupations: les fils et les filles des chefs de maisonnée, les étrangers, les servantes et les serviteurs. Au total, 2233 personnes, dont 1058 Irlandais et 413 Canadiens français.

\section{TABLEAU 3}

Adultes des différentes ethnies nés en Ontario et ayant déclaré une occupation selon leur âge et la décennie de leur naissance en 1871.

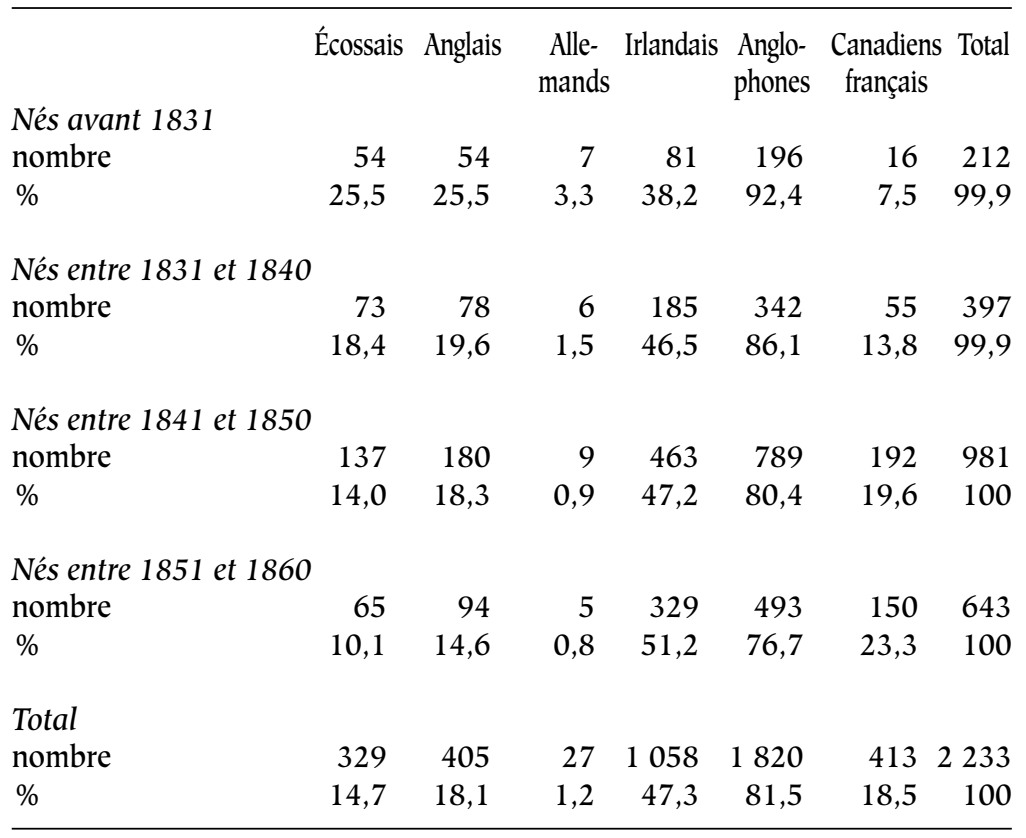

Source: APC, Recensement nominatif d'Ottawa de 1871, bobines 10013 , 10014 et 10015 .

\footnotetext{
${ }^{15}$ Pour nous en tenir aux éléments qui avaient le plus de chances d'être stables, nous nous sommes limités à ceux qui étaient nés en Ontario. Ce groupe représente $10,7 \%$ de la population de la ville, ce qui est beaucoup plus restreint que la catégorie des "persistants " que Katz situe entre 33 et $40 \%$ de la population. Michael Katz, The People of Hamilton, Canada West. Family and Class in a Mid-Nineteenth-Century City, Cambridge, Harvard University Press, 1975, p. 20.
} 
Ainsi, d'après ces chiffres, les Irlandais non seulement constituaient dès avant 1831 le groupe le plus nombreux, mais ils avaient aussi accru cette supériorité jusqu'à 1860 au moins. Bien plus, ils avaient toujours été solidement représentés aussi bien dans les quartiers riches que dans les pauvres: des taux supérieurs à $63 \%$ dans Wellington, Victoria et Saint-Georges. Pendant ce temps, les Canadiens français, bien qu'améliorant sans cesse leurs pourcentages, auraient toujours été largement minoritaires et rassemblés dans les quartiers By et Ottawa dans des proportions d'environ $80 \%$. Vu sous cet angle, il semble bien que l'objectif principal visé par les Shiners et ceux qui les appuyaient était d'étendre, par des moyens violents, leur contrôle sur la main-d'œuvre dans l'ensemble de la région. Tâche illusoire, notamment dans un contexte d'intenses rivalités ethniques à l'intérieur d'une société très hétérogène, compte tenu de l'étendue considérable du bassin de recrutement de la main-d'œuvre saisonnière canadiennefrançaise qui participait aux activités forestières dans tout l'Outaouais, ainsi que du ralentissement de l'immigration irlandaise catholique après 1850 . En d'autres mots, il s'agissait d'un conflit entre deux ethnies, toujours actuel en 1871, dont l'enjeu principal était le contrôle de la maind'œuvre dans et en dehors d'Ottawa.

En fait, Michael Cross voyait les Irlandais comme un groupe homogène catholique, au bas de l'échelle sociale, confiné à la basse ville et analphabète ${ }^{16}$. Entre 1846 et 1849 , le nombre annuel moyen d'immigrants irlandais dans les colonies britanniques en Amérique du Nord s'élevait à 57 457; il ne fut que de 14054 au cours des 10 années suivantes ${ }^{17}$. Pourtant, en plus des différences entre les Irlandais catholiques et les Canadiens français, il en existait d'aussi profondes et permanentes entre les Irlandais

\footnotetext{
${ }^{16}$ Op. cit., CHR, 1973, p. 8.

${ }^{17}$ Donald Harman Akenson, op. cit., p. 32.
} 
catholiques et protestants, comme il s'en trouvait de moins marquées à cette date entre les personnes nées en Ontario et celles nées ailleurs. C'est pourquoi nous avons tenté d'estimer les effets de cette chronologie sur la localisation des chefs de maisonnée des différentes ethnies dans la ville.

\section{TABLEAU 4}

Concentration des chefs de maisonnée dans les quartiers les plus cossus (Wellington, Victoria 1 et Saint-Georges) d'Ottawa en 1871.

\begin{tabular}{|c|c|c|c|c|c|c|c|}
\hline & Écossais & Anglais & $\begin{array}{l}\text { Alle- } \\
\text { mands }\end{array}$ & Irlandais & $\begin{array}{l}\text { Anglo- } \\
\text { phones }\end{array}$ & $\begin{array}{c}\text { Canadiens } \\
\text { français }\end{array}$ & s Total \\
\hline $\begin{array}{l}\text { Nés en Ontario } \\
\text { nombre }\end{array}$ & 53 & 63 & 6 & 118 & 240 & 8 & 248 \\
\hline effectifs & 86 & 103 & 9 & 222 & 420 & 92 & 512 \\
\hline$\%$ & 61,6 & 61,2 & 66,7 & 53,1 & 57,1 & 8,7 & 48,4 \\
\hline \multicolumn{8}{|l|}{ Nés ailleurs } \\
\hline nombre & 212 & 381 & 10 & 518 & 1121 & 72 & 1193 \\
\hline effectifs & 310 & 641 & 27 & 1197 & 2175 & 1250 & 3415 \\
\hline$\%$ & 68,4 & 59,4 & 37,0 & 43,3 & 51,5 & 5,8 & 34,8 \\
\hline \multicolumn{8}{|l|}{ Ensemble } \\
\hline nombre & 265 & 444 & 16 & 636 & 1361 & 80 & 1441 \\
\hline effectifs & 396 & 744 & 36 & 1419 & 2595 & 1342 & 3937 \\
\hline$\%$ & 66,9 & 59,7 & 44,4 & 44,8 & 52,4 & 6,0 & 36,6 \\
\hline
\end{tabular}

Source: APC, Recensement nominatif d'Ottawa de 1871, bobines 10013 , 10014 et 10015 .

Il semble qu'en général les immigrants (ceux nés ailleurs) avaient été enclins à habiter le plus près possible de leur groupe ethnique. Mais, assez souvent, ils en avaient été détournés par leur condition sociale ou leur appartenance confessionnelle. Aussi l'immigration avait-elle eu pour effet d'enraciner davantage les chefs de maisonnée écossais dans leur lieu originel de résidence et, en gros, de maintenir les Anglais là où ils étaient. Quant aux Irlandais, ils avaient, au contraire, eu tendance, à la suite de l'immigration catholique, à se concentrer davantage à la basse ville (Ottawa, By et Victoria 2), alors que les Canadiens français, 
s'étaient, de plus en plus, regroupés, là où ils étaient au départ, soit à la basse ville.

Sans doute faut-il rappeler que la population d'Ottawa, comme celle des autres localités de l'Est ontarien, s'était constituée, pour une large part, à partir de couples mariés, le plus souvent avec enfants, venus de l'extérieur de la province. D'autres couples, également avec ou sans enfants, étaient originaires des campagnes de l'Est ontarien. Il y avait aussi les migrants individuels, hommes et femmes, qui habitaient Ottawa et, fort souvent, y avaient trouvé des conjoints. Comme le peuplement de la ville s'était engagé après celui des campagnes de l'Est ontarien, le pourcentage d'épouses nées dans la province y était substantiellement inférieur à celui des cantons de Hawkesbury et d'Alfred: pour les anglophones $27 \%$ contre $39 \%$ et pour les Canadiennes françaises $12 \%$ contre $22 \%$, ce qui explique la forte demande passée et présente par les immigrants de filles à marier. Aussi $76 \%$ des épouses canadiennesfrançaises nées en Ontario s'étaient-elles unies à des conjoints nés en dehors de la province. Parmi les femmes mariées anglophones nées en Ontario, ce pourcentage était de $67 \%$. 
TABLEAU 5

Profil des épouses à Ottawa en 1871

selon leur origine ethnique, géographique et leur âge.

\begin{tabular}{|c|c|c|c|c|c|c|c|}
\hline & Écossais & Anglais & $\begin{array}{l}\text { Alle- } \\
\text { mands }\end{array}$ & Irlandais & $\begin{array}{l}\text { Anglo- } \\
\text { phones }\end{array}$ & $\begin{array}{c}\text { Canadien } \\
\text { français }\end{array}$ & is Total \\
\hline Nombre & 341 & 628 & 32 & 1078 & 2079 & 1179 & 3258 \\
\hline âge moyen & 36,1 & 35,5 & 33,2 & 36,9 & 36,3 & 34,4 & 35,6 \\
\hline \multicolumn{8}{|c|}{ Nées en Ontario } \\
\hline$\%$ & 32,8 & 24,0 & 28,1 & 27,1 & 27,1 & 11,6 & 21,5 \\
\hline âge moyen & 28,4 & 30,7 & 31,3 & 30,1 & 29,9 & 26,9 & 29,3 \\
\hline \multicolumn{8}{|l|}{ Nées ailleurs } \\
\hline nombre & 229 & $\begin{array}{r}477 \\
760\end{array}$ & $\begin{array}{r}23 \\
719\end{array}$ & $\begin{array}{r}786 \\
720\end{array}$ & $\begin{array}{r}1515 \\
729\end{array}$ & $\begin{array}{r}1042 \\
884\end{array}$ & $\begin{array}{r}2557 \\
785\end{array}$ \\
\hline$\%$ & 67,2 & 76,0 & 71,9 & 72,9 & 72,9 & 88,4 & 78,5 \\
\hline âge moyen & 39,8 & 37,1 & 34,0 & 39,3 & 38,6 & 35,4 & 37,3 \\
\hline \multicolumn{8}{|c|}{ Âge au premier enfant } \\
\hline âge moyen & 24,6 & 23,9 & 24,1 & 24,4 & 24,3 & 23,0 & 23,8 \\
\hline \multicolumn{8}{|c|}{ Lorsque nées en Ontario } \\
\hline$\%$ & 33,7 & 31,9 & 26,5 & 29,2 & 28,8 & 12,9 & 23,1 \\
\hline âge moyen & 27,5 & 25,8 & 23,9 & 24,1 & 25,2 & 22,0 & 24,6 \\
\hline \multicolumn{8}{|c|}{ Lorsque nées ailleu } \\
\hline$\%$ & 66,3 & 68,1 & 73,5 & 70,8 & 71,2 & 87,1 & 76,9 \\
\hline âge moyen & 23,1 & 23,3 & 24,2 & 24,5 & 23,9 & 23,1 & 23,6 \\
\hline
\end{tabular}

Source: APC, Recensement nominatif d'Ottawa de 1871, bobines 10013 , 10014 et 10015.

À Ottawa, étant donné le caractère plus récent du peuplement, les épouses étaient légèrement plus jeunes qu'elles ne l'étaient à Hawkesbury et à Alfred. La marge était de 2,9 années chez les Canadiennes françaises et de 5,3 ans chez les anglophones. Par contre, à la naissance de leur premier enfant, elles étaient un peu plus âgées qu'elles. Un mince écart de 1,2 années, chez les premières, et de 0,5, chez les secondes, ce qui, sans doute, pouvait quand même exprimer une certaine adaptation aux réalités urbaines. En 
effet, le régime démographique à Ottawa était sensiblement différent de celui de Hawkesbury et d'Alfred. La natalité y était plus faible que celle prévalant dans ces cantons ruraux: 6,1 \% dans l'ensemble, 6,3\% parmi les Canadiens français et seulement $1,5 \%$ chez les anglophones. Au contraire, la mortalité générale y était, par une marge substantielle, plus élevée : de 7, 9\% dans l'ensemble, de $14,3 \%$ en milieu canadien-français et de 5,4\% parmi les anglophones. Quant à la mortalité infantile, elle atteignait presque le niveau de la ville de Montréal qui se chiffrait à 32,7 décès pour 100 naissances. Dans la communauté canadiennefrançaise, elle s'élevait à $30,8 \%$, alors qu'elle n'était que de $16,9 \%$ en contexte anglophone. À Hawkesbury et à Alfred, ces taux étaient de 12,3\% parmi les Canadiens français et de 4,6\% parmi les anglophones. Même si tous les groupes ethniques d'Ottawa étaient soumis au même régime démographique, chacun d'eux y participait à sa façon. Ainsi les Canadiens français surpassaient tous les autres en ce qui concerne le taux de natalité ${ }^{18}$, de mortalité générale et de mortalité infantile. Qui oserait dire que la pauvreté et l'analphabétisme ne figuraient pas parmi les facteurs responsables de ces disparités entre les anglophones et les habitants de langue française?

\footnotetext{
${ }^{18}$ Michael Katz, op. cit., p. 33, écrivait à ce sujet: «That exception, and an interesting one, is the people born in French Canada, who formed a tiny 0,4\% of the 20-29-year-olds but accounted for two percent of the births, a disproportion consistent with trends in French-Canadian demography».
} 
TABLEAU 6

(1) Natalité, mortalité générale, croissance et

(2) mortalité infantile à Ottawa en 1871.

\begin{tabular}{lrrr}
\hline & Anglophones & $\begin{array}{c}\text { Canadiens } \\
\text { français }\end{array}$ & Total \\
$\begin{array}{l}\text { Natalité } \\
\text { nombre de naissances }\end{array}$ & 332 & 234 & 566 \\
population & 13730 & 7041 & 20771 \\
taux (\%) & 2,42 & 3,32 & 2,74 \\
Mortalité générale & & & \\
nombre de décès & 217 & 191 & 408 \\
population & 13730 & 7041 & 20771 \\
taux (\%) & 1,58 & 2,71 & 1,96 \\
& & & \\
Croissance & 115 & 43 & 158 \\
nombre & 13730 & 7041 & 20771 \\
population & 0,84 & 0,61 & 0,78 \\
taux (\%) & & & \\
Mortalité infantile & 56 & 72 & 128 \\
nombre de décès & 332 & 234 & 566 \\
nombre de naissances & 16,9 & 30,8 & 22,6 \\
taux & & & \\
\hline Source: APC, Recense & & & \\
\hline
\end{tabular}

Source: APC, Recensement nominatif d'Ottawa de 1871, bobines 10013 , 10014 et 10015.

Étant donné le niveau très élevé de la mortalité, il paraît évident que la croissance de la ville dépendait beaucoup plus d'une immigration soutenue que de ses apports naturels.

Contrairement aux chefs de maisonnée et aux épouses anglophones, les enfants adultes qui résidaient avec eux et avaient déclaré des occupations étaient, pour la plupart, nés en Ontario. Entre eux et les Canadiens français de même catégorie, il y avait, à cet égard, un décalage énorme : les premiers, excepté les Anglais, y étaient nés dans une proportion de $61,7 \%$ et les seconds de $36,8 \%$. Un peu plus âgés en moyenne que les Canadiens français, ces jeunes anglophones étaient tous au début de la vingtaine. Dans tous les groupes ethniques, les individus nés ailleurs étaient 
un peu plus âgés que ceux nés en Ontario. Notons enfin, ce qui est certainement un indicateur du statut économique des personnes en question et de leurs familles, que c'est parmi les Anglais, les Écossais et les Allemands que le pourcentage des femmes décrites comme ayant une occupation était le plus faible: un taux de $9,6 \%$ contre $22,1 \%$ chez les Irlandais et de $24,8 \%$ dans les maisonnées canadiennesfrançaises. À ce sujet, Michael Katz écrivait:

women who worked could be considered by and large a homogeneous group with respect to wealth: they were poor, at the very bottom of the work force. Women who did not work fared according to the means which they had been left by men ${ }^{19}$.

\section{TABLEAU 7}

Enfants de la famille*, membres de la maisonnée,

sans en être les chefs, ayant déclaré une occupation à Ottawa en 1871.

\begin{tabular}{|c|c|c|c|c|c|c|c|}
\hline & Écossais & Anglais & $\begin{array}{l}\text { Alle- } \\
\text { mands }\end{array}$ & Irlandais & $\begin{array}{l}\text { Anglo- } \\
\text { phones }\end{array}$ & $\begin{array}{c}\text { Canadiens } \\
\text { français }\end{array}$ & Total \\
\hline Nombre & 93 & 129 & 6 & 417 & 645 & 331 & 976 \\
\hline âge moyen & 22,2 & 21,4 & 21,2 & 21,2 & 21,4 & 20,4 & 21,1 \\
\hline \multicolumn{7}{|c|}{ Nés en Ontario } & 520 \\
\hline$\%$ & 69,9 & 41,9 & 66,7 & 65,9 & 61,7 & 36,8 & 53,3 \\
\hline âge moyen & 21,4 & 20,5 & 22,5 & 20,7 & 20,8 & 19,3 & 20,5 \\
\hline \multicolumn{8}{|l|}{ Nés ailleurs } \\
\hline$\%$ & 30,1 & 58,1 & 33,3 & 34,0 & 38,3 & 63,2 & 46,7 \\
\hline âge moyen & 24,2 & 22,1 & 18,5 & 22,2 & 22,4 & 21,0 & 21,8 \\
\hline \multicolumn{8}{|l|}{ Femmes } \\
\hline$\%$ & 10,7 & 7,7 & & 22,1 & 17,7 & 24,8 & 20,1 \\
\hline
\end{tabular}

Source: APC, Recensement nominatif d'Ottawa de 1871, bobines 10013 , 10014 et 10015.

* Les servantes et les serviteurs résidant chez leurs parents et travaillant à l'extérieur ne sont pas comptés ici.

${ }^{19}$ Michael Katz, op. cit., p. 60. 
Bien plus, dans les résidences privées, ce qui inclut les maisons de pension et les hôtels, ainsi que les institutions privées, il y avait des étrangers en résidence qui avaient déclaré une grande variété d'occupations. Il s'agissait d'employés, parfois d'apprentis, de résidents et, le plus souvent, de simples pensionnaires. Comme de raison, le nombre des chefs de maisonnées qui les abritaient n'égalait pas le nombre total des chefs de maisonnée puisque seulement $8,9 \%$ des chefs de maisonnée anglophones et $7,3 \%$ des Canadiens français se trouvaient dans cette situation. Parmi les anglophones, ces pourcentages variaient entre 12,9\% parmi les Écossais, 9,9\% chez les Anglais et 7,0\% parmi les Irlandais. Quant aux étrangers eux-mêmes, un grand nombre provenait du même groupe ethnique que leurs hôtes, soit $47 \%$ dans le cas des Écossais, 50 \% dans celui des Anglais, 59\% dans celui des Irlandais et $70 \%$ dans celui des Canadiens français. 


\section{DisPARITÉS SOCIO-ÉCONOMIQUES ET CULTURELLES À OTTAWA EN 1871}

\section{TABLEAU 8}

Étrangers ayant déclaré une occupation et vivant dans la maisonnée sans en être les chefs à Ottawa en $1871 .^{*}$

Écossais Anglais Alle- Irlandais Anglo- Canadiens Total mands phones français

1. Chefs de maisonnée avec étrangers dans la maison

$\begin{array}{lrrrrrrr}\text { nombre } & 51 & 74 & 6 & 99 & 230 & 98 & 328 \\ \% & 12,9 & 9,9 & 16,7 & 7,0 & 8,7 & 7,3 & 8,2\end{array}$

2. Étrangers vivant dans les maisonnées

Écossais

$\begin{array}{llllllll}\text { nombre } & 42 & 32 & 0 & 23 & 97 & 11 & 108\end{array}$

$\begin{array}{lllllll}\% & 47,2 & 18,6 & 10,8 & 20,2 & 3,4 & 13,5\end{array}$

Anglais

$\begin{array}{lrrrrrrr}\text { nombre } & 12 & 86 & 2 & 52 & 152 & 9 & 161\end{array}$

$\begin{array}{llllllll}\% & 13,5 & 50,0 & 33,3 & 24,5 & 31,7 & 2,8 & 20,2\end{array}$

Allemands

$\begin{array}{lllllllr}\text { nombre } & 1 & 2 & 0 & 0 & 3 & 9 & 12\end{array}$

$\%$

Irlandais catholiques

$\begin{array}{lllll}1,1 & 1,2 & 0,6 & 2,8 & 1,5\end{array}$

nombre

$\%$

$\begin{array}{rrrrrrr}11 & 19 & 0 & 73 & 103 & 60 & 163 \\ 12,3 & 11,0 & & 34,4 & 21,5 & 18,9 & 20,4\end{array}$

Irlandais protestants nombre

$\%$

Canadiens français

nombre

$\%$

total

nombre

$\%$

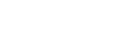

$\begin{array}{lllllll}18 & 25 & 4 & 53 & 100 & 5 & 105\end{array}$

$\begin{array}{lllllll}20,2 & 14,5 & 66,7 & 25,0 & 20,9 & 1,6 & 13,2\end{array}$

$\begin{array}{rrrrrrr}5 & 8 & 0 & 11 & 24 & 224 & 248\end{array}$

$\begin{array}{llllll}5,6 & 4,6 & 5,2 & 5,0 & 70,4 & 31,1\end{array}$

$\begin{array}{lllllll}89 & 172 & 6 & 212 & 479 & 318 & 797\end{array}$

$\begin{array}{lllllll}99,9 & 99,9 & 100 & 99,9 & 99,9 & 99,9 & 99,9\end{array}$

3. Femmes

nombre

$\%$

âge moyen

$\begin{array}{rrrrrrr}14 & 13 & 1 & 24 & 52 & 167 & 219 \\ 15,7 & 7,5 & 16,7 & 11,3 & 10,8 & 52,5 & 27,5 \\ 23,7 & 33,2 & 19,0 & 24,5 & 28,6 & 21,7 & 22,8\end{array}$

4. Nés en Ontario

Anglophones

$\begin{array}{llllllll}\text { nombre } & 28 & 47 & 1 & 56 & 132 & 19 & 151\end{array}$

$\begin{array}{llllllll}\% & 31,5 & 27,3 & 16,7 & 26,4 & 27,5 & 6,0 & 18,9\end{array}$

Canadiens français nombre

$\%$

$\begin{array}{rrrrrrr}2 & 1 & 0 & 1 & 4 & 33 & 37\end{array}$

$\begin{array}{llllll}2,2 & 0,6 & 0,5 & 0,8 & 10,4 & 4,6\end{array}$

5. Âge des étrangers nés en Ontario

ailleurs

$\begin{array}{lllllll}21,7 & 23,9 & 18,0 & 26,2 & 24,4 & 24,2 & 24,3\end{array}$

$\begin{array}{lllllll}27,1 & 28,3 & 37,0 & 38,9 & 32,6 & 29,6 & 31,5\end{array}$

ensemble

$25,3 \quad 27,0 \quad 33,8$

$35,5 \quad 30,5 \quad 28,8 \quad 29,8$

Sources: APC, Recensement nominatif d'Ottawa de 1871, bobines 10013 , 10014 et 10015 . $^{*}$ Les domestiques sont traités séparément. 
Notons aussi que ces jeunes adultes qui avaient quitté leur famille, parfois leur province et même leur pays, bien que plus âgés que les enfants adultes qui vivaient encore avec leurs parents (tableau 7), étaient moins souvent nés en Ontario qu'eux. Néanmoins, parmi eux, la proportion des individus nés dans la province était quand même supérieure à celle des chefs de maisonnée, soit 18,9\% contre $13,0 \%$ (tableau 2). Enfin, dans cette catégorie d'individus en voie d'établissement, le pourcentage de femmes était beaucoup plus élevé parmi les Canadiens français que dans les autres groupes ethniques, soit $47,6 \%$ contre $18,4 \%$. Cela s'explique surtout par le grand nombre de personnes adonnées à l'enseignement et à la charité dans les institutions religieuses catholiques.

En plus de ces étrangers, il y avait le groupe des domestiques ${ }^{20}$, au nombre de 848 , qui était composé de femmes dans une proportion de $86 \%$. Les uns étaient recensés comme membres de la famille, mais travaillaient dans d'autres maisonnées sans y résider habituellement. Cette catégorie représentait $13,7 \%$ de tous les domestiques et elle se recrutait parmi les Irlandais et les Canadiens français dans une proportion de $96 \%$. Les autres, au nombre de 732, étaient recensés dans la maisonnée de leurs patrons chez qui ils logeaient pendant la durée de leur emploi. Entre les chefs de maisonnée des différents groupes ethniques qui avaient des domestiques, une séparation très nette existait entre les plus riches qui engageaient des servantes et des serviteurs en dehors de leur propre groupe et les plus pauvres qui les alimentaient. En effet, les Écossais, les Anglais et les Allemands, qui ne représentaient que $30 \%$ des chefs de maisonnée, engageaient $46 \%$ des domestiques. Comme leurs compatriotes de même origine n'en fournissaient que $17,4 \%$, il leur avait fallu en recruter

${ }^{20} \mathrm{Au}$ aujet des domestiques de Toronto, Québec et Halifax en 1871, voir Claudette Lacelle, Urban Domestic Servants in $19^{\text {th }}$ Century Canada, Ottawa, National Historic Parks and Sight, 1987, 254 p. 
240 dans les autres groupes ethniques et confessionnels, soit 224 parmi les Irlandais et seulement $16 \mathrm{chez}$ les Canadiens français. Ainsi, les Canadiens français étaient parmi les plus pauvres, mais ils n'avaient eu, sans doute à cause de la barrière linguistique, qu'un accès marginal à ces emplois, partagés très inégalement entre les groupes ethniques les plus défavorisés. En effet, sur ces 240 domestiques des deux sexes recherchés par les Écossais, les Anglais et les Allemands, 6,7\% étaient des Canadiens français, $22,5 \%$ des Irlandais protestants et $70,8 \%$ des Irlandais catholiques. Bien plus, $40 \%$ d'entre eux étaient nés en Ontario, 26,2\% au Québec et 33,7\% dans les îles Britanniques et aux États-Unis. 


\section{TABLEAU 9}

Servantes et serviteurs dans les maisonnées et ailleurs* selon leur origine ethnique et géographique et celle des chefs de maisonnée qui les employaient à Ottawa en 1871.

\begin{tabular}{lccrrrrrr}
\hline & Écossais & Anglais & \multicolumn{2}{c}{$\begin{array}{c}\text { Alle- } \\
\text { mands Irlandais }\end{array}$} & $\begin{array}{c}\text { Anglo- } \\
\text { phones }\end{array}$ & Canadiens \\
& \multicolumn{7}{c}{ français } \\
Domestiques selon l'origine ethnique des chefs de maisonnée \\
nombre & 126 & 257 & 5 & 249 & 637 & 211 & 848 \\
chefs de maisonnée & 396 & 744 & 36 & 1419 & 2595 & 1342 & 3937 \\
$\%$ & 31,8 & 34,5 & 13,9 & 17,5 & 24,5 & 15,7 & 21,5
\end{tabular}

Domestiques selon leur appartenance ethnique

$\begin{array}{lrrrrrrr}\text { nombre } & 64 & 80 & 4 & 473 & 621 & 227 & 848 \\ \text { chefs de maisonnée } & 396 & 744 & 36 & 1419 & 2595 & 1342 & 3937 \\ \% & 16,2 & 10,7 & 11,1 & 33,3 & 23,9 & 16,9 & 21,5\end{array}$

Nés en Ontario

$\begin{array}{lrrrrrrr}\text { nombre } & 32 & 26 & 2 & 223 & 283 & 39 & 322 \\ \% & 50,0 & 32,5 & 50,0 & 47,1 & 45,6 & 17,2 & 38\end{array}$

Nés au Québec

$\begin{array}{lrrrrrrr}\text { nombre } & 10 & 10 & 0 & 68 & 88 & 187 & 275 \\ \% & 15,6 & 12,5 & & 14,4 & 14,2 & 82,4 & 32,4\end{array}$

Nés ailleurs

$\begin{array}{lrrrrrrr}\text { nombre } & 22 & 44 & 2 & 182 & 250 & 1 & 251 \\ \% & 34,4 & 55,0 & 50,0 & 38,5 & 40,2 & 0,4 & 29,6\end{array}$

Total

$\begin{array}{lrrrrrrr}\text { nombre } & 64 & 80 & 4 & 473 & 621 & 227 & 848 \\ \% & 100 & 100 & 100 & 100 & 100 & 100 & 100 \\ \text { âge moyen } & 23,9 & 23,4 & 21,1 & 22,3 & 23,0 & 22,5 & 22,9\end{array}$

Femmes

\begin{tabular}{lrrrrrrr} 
nombre & 57 & 67 & 3 & 408 & 535 & 194 & 729 \\
$\%$ & 89,1 & 83,7 & 75,0 & 86,2 & 86,1 & 85,5 & 86 \\
\hline
\end{tabular}

Source: APC, Recensement nominatif d'Ottawa de 1871, bobines 10013 , 10014 et 10015 .

* Travaillaient dans des institutions religieuses et autres ou dans des hôtels.

Dans l'ensemble, il existait un énorme contraste, quant au lieu d'origine, entre les domestiques anglophones et les Canadiens français. Alors que les premiers provenaient de l'Ontario et des îles Britanniques dans des proportions 
presque égales, $46 \%$ de la province et $40 \%$ d'ailleurs, $82 \%$ des Canadiens français étaient nés au Québec. Ces domestiques étaient un peu plus âgés que les jeunes adultes habitant dans les maisonnées, mais beaucoup moins que les étrangers y résidant.

Les différences entre les domestiques d'origine française et irlandaise en ce qui concerne l'accès au marché du travail n'est qu'un indice de l'existence d'une fracture à la fois ethnique, sociale, économique et religieuse, qui se trouve, par ailleurs, confirmée par le poids relatif de chacun de ces groupes dans les quartiers les plus pauvres d'Ottawa, c'est-à-dire Ottawa-By. En effet, la moitié de la population de la ville y était concentrée, mais seulement $27 \%$ des Écossais-Anglais-Allemands et $43 \%$ des Irlandais y étaient présents. Par contre, $80 \%$ des Canadiens français s'y trouvaient. C'est d'ailleurs dans Ottawa-By que 69\% des catholiques de la ville étaient rassemblés. La proportion des Irlandais catholiques dans ces quartiers ne surpassait celle des autres anglophones de même religion que par une marge de $4 \%$, alors que les Canadiens français y étaient deux fois plus nombreux que tous les autres réunis. Étant donné ces chiffres, il allait de soi que tous les protestants étaient sous-représentés dans ces quartiers. 


\section{TABLEAU 10}

Concentration des groupes ethniques et religieux dans les quartiers Ottawa-By en 1871.

\begin{tabular}{lcccc}
\hline & $\begin{array}{c}\text { Écossais- } \\
\text { Anglais- } \\
\text { Allemands }\end{array}$ & Irlandais & $\begin{array}{c}\text { Canadiens } \\
\text { français }\end{array}$ & Total \\
$\begin{array}{l}\text { Population totale } \\
\text { effectifs Ottawa-By }\end{array}$ & 1615 & 3293 & 5615 & 10523 \\
$\begin{array}{l}\text { population totale } \\
\%\end{array}$ & 5892 & 7734 & 7087 & 20803 \\
& 27,0 & 42,6 & 80,3 & 50,6 \\
$\begin{array}{l}\text { Population catholique } \\
\text { effectifs Ottawa-By }\end{array}$ & 217 & 2633 & 5609 & 8459 \\
$\begin{array}{l}\text { population totale } \\
\text { \% }\end{array}$ & 421 & 4730 & 7054 & 12305 \\
& 51,5 & 55,7 & 79,5 & 68,7 \\
$\begin{array}{l}\text { Population protestante } \\
\text { effectifs Ottawa-By }\end{array}$ & & & & \\
population totale & 1398 & 660 & 6 & 2064 \\
$\%$ & 5561 & 3004 & 33 & 8598 \\
\hline
\end{tabular}

Source: APC, Recensement nominatif d'Ottawa de 1871, bobines 10013 , 10014 et 10015 .

Au sommet de la pyramide sociale, il y avait donc une classe dirigeante recrutée parmi les Écossais, les Anglais, les Allemands et les Irlandais protestants. À un niveau plus bas, se trouvaient les Irlandais catholiques et les Canadiens français. L'originalité de ces derniers, comme c'était le cas au Québec, aux États-Unis et ailleurs en Ontario, tenait non seulement à leur homogénéité linguistique, à leur grande pauvreté, à leur localisation et à leur régime démographique, mais aussi à leur degré très élevé d'appartenance à une seule religion, ainsi qu'à leur taux relativement très élevé d'analphabétisme ${ }^{21}$.

${ }^{21}$ Dans notre texte sur Hawkesbury et Alfred, nous avons déjà fait état des travaux de Vicero, Roby, Ramirez et Frenette sur les Canadiens français aux États-Unis. Le dernier en date est celui de Jean Lamarre, Les Canadiens français du Michigan. Leur contribution dans le développement de la vallée de la Saginaw et de la péninsule de la Keweena, 1840-1914, Sillery, Septentrion, 2000, 226 p. 


\section{II - Religion}

Tout comme la langue, l'affiliation à une confession religieuse constituait un élément important de la culture. Sur ce point, William L. Morton affirmait non sans une bonne dose d'exagération:

religion - not wealth, and not politics - was the chief concern, the main ideal occupation of Canadians, both British and French [...]. All politics were indeed sectarian ${ }^{22}$.

Disons plutôt que l'immense majorité des individus se rattachait à l'une ou l'autre des multiples croyances religieuses qui avaient cours dans la ville et ailleurs sur le continent. Il est vrai que certaines Églises regroupaient plus de fidèles et avaient plus de poids dans la société globale que d'autres, mais aucune n'accaparait tous les individus d'une même ethnie, à l'exception des Canadiens français. Ainsi, seulement $40 \%$ des chefs de maisonnée d'origine écossaise étaient presbytériens, mais plus de $60 \%$ des Anglais et $50 \%$ des Allemands se rattachaient à l'Église d'Angleterre, tandis que $60 \%$ des Irlandais se déclaraient catholiques. Pour déceler l'existence d'une solidarité entre les membres de ces diverses communautés protestantes anglophones, sans doute devrait-on s'en remettre à l'ordre d'Orange, en pleine expansion au XIX ${ }^{\mathrm{e}}$ siècle, qui s'était donné pour mission de rallier tous ceux ayant le sentiment que le protestantisme, ainsi que la loyauté à la Couronne et à l'Empire britannique, pouvaient être menacés. Jusqu'en 1920, l'influence de cette société secrète hostile au catholicisme augmenta, particulièrement en Ontario, surtout parmi les classes dirigeantes, comme le disent Houston et Smyth:

Orangeism and toryism were philosophically complementary but socially incompatible. Nevertheless, the order provided for tory candidates a measure of voting power and public obstructionism

${ }^{22}$ Cité dans Cecil Houston and William Smyth, The Sash Canada Wore. A Historical Geograpy of the Orange Order in Canada, Toronto, UTP, 1980, p. 143. 
at the polls [...]. Party compromise, variable leadership, actual disagreement with many of the policies of the Conservatives, and local political interests made the order an ineffectual party machine ${ }^{23}$.

Mal à l'aise jusqu'à un certain point avec les conservateurs, les Orangistes l'étaient bien davantage avec les libéraux, même si certains d'entre eux avaient pu, à un moment ou l'autre, faire partie de leur organisation. Nous avons beaucoup insisté, avec raison, sur les pressions réussies des Orangistes en faveur de l'adoption du règlement XVII. Et, pourtant, le rôle de $\mathrm{M}^{\text {gr }}$ Fallon, l'évêque catholique irlandais de London, un des partisans avoué et actif de cette mesure, fut loin d'être négligeable. En vérité, la force des Églises protestantes, bien que divisées entre elles, provenait de leurs rapports avec une minorité qui constituait le plus gros des classes dirigeantes. Ainsi, seulement 30,4\% des chefs de maisonnées se réclamaient des Églises d'Angleterre, d'Écosse et presbytérienne ${ }^{24}$, mais leurs membres étaient beaucoup plus intimement associés aux affaires et à la direction des institutions publiques que les catholiques. Ces liens furent d'ailleurs renforcés lorsque Ottawa devint la capitale nationale.

Pour contrer ce réseau dominant, un autre pouvoir s'était développé. Celui-ci avait permis au clergé catholique du Canada-Est de s'ériger en classe dominante et, pour cette raison, il avait été en mesure, même depuis la création, sous son égide, du diocèse de Kingston en 1826, de présider au développement des institutions dans l'ensemble de la province et, plus particulièrement, dans une partie de l'Est. Mais, en exerçant ce pouvoir, comme il le fit au plus grand profit des Canadiens français, il contribua non seulement à leur isolement culturel, mais aussi à attiser les rivalités existantes entre ceux-ci et les Irlandais

\footnotetext{
${ }^{23}$ Ibid., p. 147, 149.

${ }^{24}$ Le recensement distingue entre l'Église presbytérienne et l'Église d'Écosse.
} 
catholiques. Car, une fois l'épisode des Shiners à peu près terminé, l'antagonisme entre les Canadiens français et les Irlandais, en progressant de la taverne aux institutions ecclésiastiques, prit des formes plus subtiles.

Ainsi, de 1827 à 1836, à l'époque des violents affrontements entre les Irlandais catholiques et les Canadiens français, six prêtres irlandais ${ }^{25}$ qui, assez souvent, prirent à des degrés divers parti pour l'un ou l'autre des belligérants, se succédèrent à la cure de Bytown. Puis, de 1836 à 1842, au moment de la guerre des Shiners, le curé, Jean-François Cannon, né de père irlandais et de mère canadiennefrançaise, parfaitement à l'aise en anglais et en français, avait dirigé la paroisse et, apparemment, il ne semble pas avoir trop subi les contrecoups du tumulte des années 1836-1838. Cependant, à son départ en 1842, l'évêque de Kingston avait écrit: "Je n'ai absolument aucun sujet propre à ce lieu, difficile à conduire à cause des partis qui y existent ${ }^{26}{ }^{\prime}$. Quelques mois plus tard, le curé A. Neyron, affirma: «La division la plus vive se fait toujours remarquer dans la congrégation». Le choix de Patrick Phelan, un prêtre irlandais expérimenté, enthousiaste et sensible au bilinguisme, fut peut-être le bon puisque, seulement quelques mois après son installation, il prétendit avoir vraiment calmé les esprits par son attention soutenue aux sensibilités linguistiques des deux communautés. Même si le bilinguisme ne pouvait constituer la panacée au problème de la coexistence difficile entre Irlandais catholiques et Canadiens français, il en était quand même un ingrédient essentiel.

\footnotetext{
${ }^{25}$ La liste des curés et des vicaires (1827-1844) apparaît dans Robert Choquette, op. cit., p. 66. Non seulement eut-on des questions sur le caractère moral de quelques-uns de ces curés, mais l'on découvrit plus tard que l'un d'eux n'était pas prêtre.

${ }^{26}$ Robert Choquette, op. cit., p. 69.
} 
Mais l'évêque de Montréal avait formé le projet d'attribuer la cure de Bytown à un ordre religieux d'origine française ${ }^{27}$. Dans son esprit, cela n'était qu'une étape en vue de la création prochaine d'un nouveau diocèse, dont le siège serait à Bytown et qui inclurait certains comtés du Canada-Est où les Canadiens français étaient déjà majoritaires. Le curé Phelan, avant sa nomination comme évêque coadjuteur à Kingston, s'était d'abord objecté vigoureusement à ce transfert de la cure en faveur des oblats, puis il se plia à la volonté de son supérieur. Cela facilita la création, en 1847, du diocèse de Bytown sous la dépendance de la province ecclésiastique de Québec. Ces événements eurent d'autant plus de résonnance parmi les Irlandais catholiques que les oblats étaient des francophones unilingues, alors que les anglophones catholiques étaient majoritaires et qu'ils le restèrent jusqu'au milieu des années 1860, non seulement dans la ville et dans la zone ontarienne, mais aussi dans l'ensemble du diocèse ${ }^{28}$. À vrai dire, les prêtres ravivèrent d'autant plus les craintes des Irlandais qui n'avaient jamais vu d'un bon œil la progression rapide des Canadiens français dans la ville et la région, accélérée qu'elle devait être par l'inclusion d'une population à dominance québécoise. Aussi, en 1844, les Irlandais pratiquèrent-ils une certaine obstruction contre leur nouveau curé, l'oblat unilingue Adrien Telmon, mais personne, parmi eux, ne se leva avant $1855^{29}$ pour clamer bien haut leur frustration collective.

\footnotetext{
${ }^{27}$ Question discutée dans Fernand Ouellet et René Dionne, Journal du père Dominique Du Ranquet, s.j., 1843, Ottawa, Vermillon, 2000, p. 30-34.

${ }^{28}$ Robert Choquette, op. cit., p. 143.

${ }^{29}$ En 1832, Lartigue avait projeté d'établir dans le Haut-Canada une succession d'évêques canadiens-français qui y introduiraient les pratiques et la discipline ecclésiastiques en vigueur dans le Bas-Canada. Cité dans Roger Guindon, op. cit., p. 143. En 1855, 21 prêtres anglophones protestèrent en rappelant que le Canada-Ouest était une province anglaise. En effet, il y avait $\mathrm{M}^{\mathrm{gr}}$ Guigues à Ottawa, $\mathrm{M}^{\mathrm{gr}}$ Gaulin à Kingston, $\mathrm{M}^{\mathrm{gr}}$ Pinsonneault à London et $\mathrm{M}^{\mathrm{r}}$ Charbonnel à Toronto, tous relevant de l'archevêque de Québec. Pour une analyse de ces nominations voir Robert Choquette, op. cit., p. 91-144.
} 
Les Irlandais catholiques les mieux informés eurent certainement très tôt le sentiment qu'une force supérieure, celle de l'épiscopat canadien-français du Canada-Est, les traitait comme s'ils étaient de peu de conséquence ${ }^{30}$. Tentant de minimiser les répercussions de la création de son diocèse sur les catholiques irlandais, $\mathrm{M}^{\text {gr }}$ Guigues se fit, dès 1847 , l'apôtre du bilinguisme:

l'évêque doit être en état d'entendre et de parler à son peuple. Il est donc urgent que le nouvel évêque et presque tout son clergé se mettent immédiatement à [...] l'étude [de l'anglais]; il n'y a en ce moment que quelques prêtres qui sachent cette langue, et dès à présent cette connaissance est absolument nécessaire: plus de la moitié de ce nouveau diocèse est composé de personnes d'origine britannique, même dans cette partie du Bas-Canada qui doit être renfermée dans le nouveau diocèse $[\ldots]^{31}$.

En 1855, $\mathrm{M}^{\mathrm{gr}}$ Guigues, répondant sans doute aux critiques formulées par une partie du clergé irlandais, affirma:

La moitié des catholiques du diocèse sont ou seront Canadiens [français], le diocèse touche au Bas-Canada et a adopté déjà la plus grande partie des usages religieux canadiens[-français]. Un évêque français se prête plus facilement qu'un Irlandais à parler la langue étrangère et à se dévouer à une famille différente de la sienne par la nationalité. [...] Le futur évêque doit être pris dans le sein de la nation canadienne ou française ${ }^{32}$.

Vingt-sept ans plus tard, alors que ses prévisions démographiques se seront réalisées, $M^{\text {gr }}$ Guigues sera beaucoup plus à l'aise pour justifier son choix de Joseph-Thomas Duhamel comme son successeur:

\footnotetext{
${ }^{30}$ Ce fut certainement le cas des évêques Macdonald, Horan et, plus fortement encore, Lynch, les uns protestant contre le traitement infligé aux Irlandais et les autres résistant de plusieurs façons à la hiérarchie canadienne-française. Déjà, en 1827, Alexander Macdonald écrivait : «mes démarches en faveur des catholiques du Haut-Canada [auprès de l'évêque de Québec] furent toujours accueillies avec apathie et indifférence comme si les âmes des Écossais, des Irlandais et des autres habitants de ces bois n'avaient pas été rachetées au même prix...", Roger Guindon, op. cit., p. 2.

${ }^{31}$ Cité dans Robert Choquette, op. cit., p. 146s.

${ }^{32}$ Cité dans Robert Choquette, op. cit., p. 150.
} 
$1^{\circ}$ La plus grande partie des diocésains sont Canadiens français. $2^{\circ}$ L'augmentation des catholiques irlandais a été peu considérable dans le diocèse $[. .$.$] tandis que l'augmentation$ canadienne-française a été très nombreuse $[\ldots] .3^{\circ} \mathrm{Je}$ n'ai pu me dissimuler que, si un évêque irlandais était désigné, les Canadiens français n'en obtiendraient pas la justice qu'un évêque français accorderait aux Irlandais [...]. Mon choix a été déterminé uniquement par l'intérêt catholique et non par celui de l'origine ${ }^{33}$.

En vérité, en 1874 comme en 1847 et en 1855, les considérations nationales, inspirées d'une conception de l'identité liant étroitement langue française et religion catholique, avaient surtout dicté les décisions de l'épiscopat canadien-français du Québec, appuyé par Rome, en ce qui concerne les liens entre le diocèse d'Ottawa et la province ecclésiastique de Québec.

En 1871, les Canadiens français, devenus majoritaires dans le reste du diocèse, représentaient $58 \%$ des chefs de maisonnée catholiques d'Ottawa la ville. Les Irlandais catholiques venaient au second rang avec un pourcentage de $37 \%$, ce qui ne laissait que $5 \%$ aux autres. Les Canadiens français se réclamaient du catholicisme dans une proportion de 99,6\%, les Irlandais de 60,4\% et les Écossais, les Anglais et les Allemands réunis de seulement 7,7\%. Alors que l'Église d'Angleterre ralliait 62,2\% des Anglais, les Eglises presbytérienne et d'Écosse servaient 58,4\% des Écossais.

${ }^{33}$ Cité par Roger Guindon, op. cit., p. 50s. 
DisParitéS SOCIO-ÉCONOMIQUES ET CULTURELLES À OTTAWA EN 1871

TABLEAU 11

Religion des chefs de maisonnée à Ottawa en 1871.

\begin{tabular}{cccc}
\hline Écossais Anglais & $\begin{array}{c}\text { Alle- } \\
\text { mands }\end{array}$ & Irlandais Anglo- Canadiens Total \\
phones & français
\end{tabular}

Église catholique

$\begin{array}{lrrrrrrr}\text { nombre } & 41 & 43 & 7 & 857 & 948 & 1337 & 2285 \\ \% & 10,1 & 5,8 & 19,4 & 60,4 & 36,4 & 99,6 & 57,9\end{array}$

Église anglicane

nombre

$\%$

$\begin{array}{rrrrrrr}46 & 463 & 18 & 274 & 801 & 3 & 804 \\ 11,3 & 62,2 & 50,0 & 19,3 & 30,7 & & 20,4\end{array}$

Église presbytérienne

nombre

$\%$

$\begin{array}{rrrrrrr}163 & 42 & 4 & 83 & 292 & 0 & 292 \\ 40,0 & 5,6 & 11,1 & 5,8 & 11,2 & & 7,4\end{array}$

Église d'Écosse

nombre

$\%$

$\begin{array}{rrrrrrr}75 & 12 & 2 & 20 & 109 & 0 & 109 \\ 18,4 & 1,6 & 5,5 & 1,4 & 4,2 & & 2,8\end{array}$

Église méthodiste

nombre

$\%$

$\begin{array}{rrrrrrr}32 & 128 & 2 & 152 & 314 & 1 & 315 \\ 7,9 & 17,2 & 5,5 & 10,7 & 12,0 & 0 & 8,0\end{array}$

Église baptiste

nombre

$\%$

$\begin{array}{rrrrrrr}10 & 17 & 1 & 10 & 38 & 0 & 38 \\ 2,4 & 2,3 & 2,8 & 0,7 & 1,5 & 0 & 1,0\end{array}$

Autres

$\begin{array}{lrrrrrrr}\text { nombre } & 29 & 39 & 2 & 23 & 93 & 1 & 94 \\ \% & 9,8 & 5,2 & 5,5 & 1,6 & 4,0 & 0,1 & 4,0\end{array}$

Total

$\begin{array}{lllllllll}\text { nombre } & 396 & 744 & 36 & 1419 & 2595 & 1342 & 3937\end{array}$

$\begin{array}{llllllll}\% & 99,9 & 99,9 & 99,8 & 99,8 & 100 & 99,9 & 100\end{array}$

Source: APC, Recensement nominatif d'Ottawa de 1871, bobines 10013 , 10014 et 10015 .

La répartition des épouses entre les diverses confessions religieuses n'était pas, dans l'ensemble, tellement différente de celle des chefs de maisonnée. Mais, en regardant les 
choses de plus près, des disparités significatives de taux apparaissent, surtout parmi les protestants. Par le biais des mariages exogames, on peut ainsi lever le voile sur certains aspects des rapports interethniques et interconfessionnels.

\section{TABLEAU 12}

Religion des épouses à Ottawa en 1871.

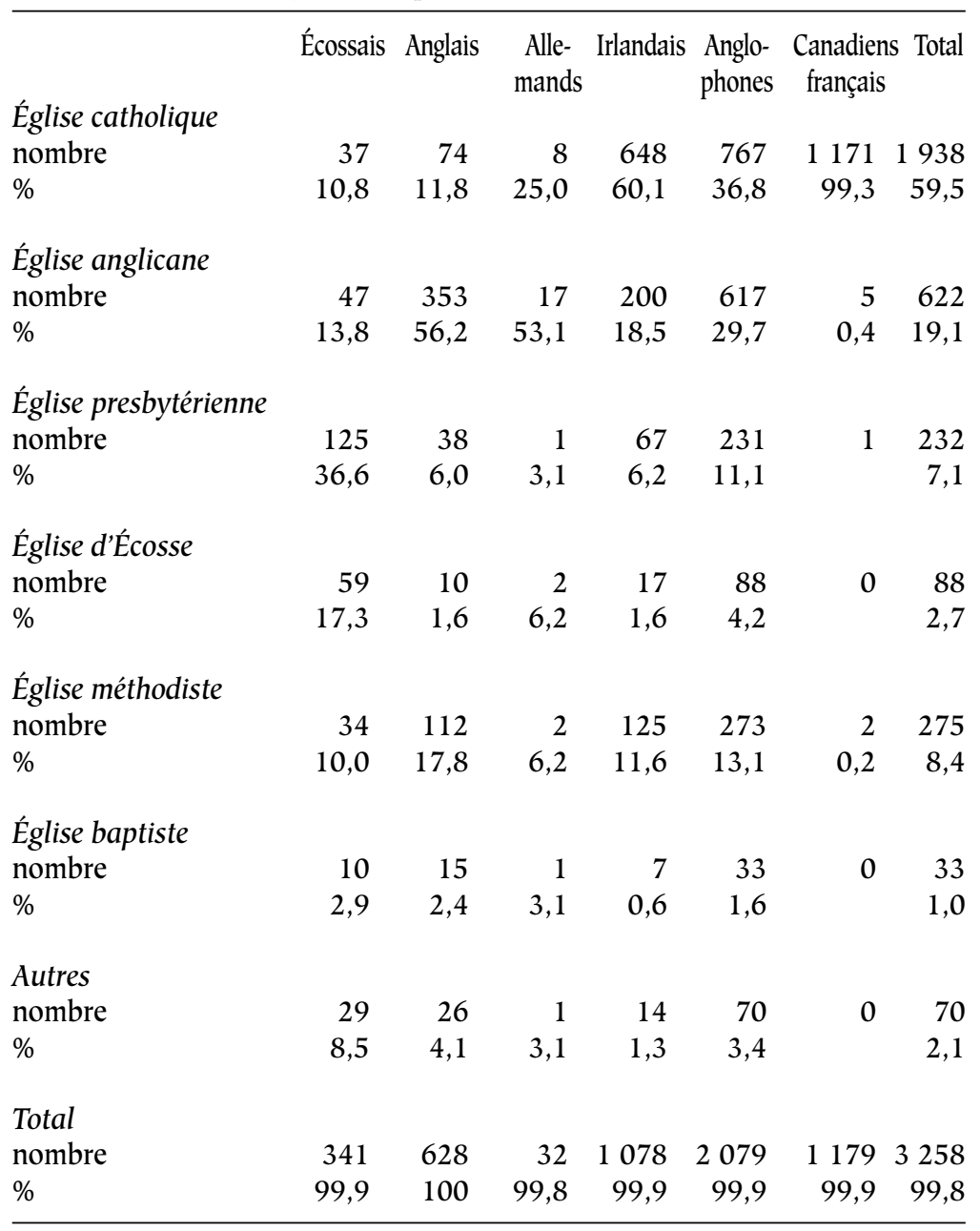

Source: APC, Recensement nominatif d'Ottawa de 1871, bobines 10 013, 10014 et 10015 . 
À Ottawa, l'exogamie était deux fois plus grande qu'à Hawkesbury et à Alfred: $22,5 \%$ des couples de la ville contre $12 \%$ de ceux de ces cantons ruraux y étaient composés de conjoints différents par l'origine ethnique et par la religion, ou par les deux à la fois. Il est vrai que, dans les cantons à dominance rurale de Malden et de Sandwich (Essex), le taux moyen égalait celui d'Ottawa. Mais, à cet endroit, les taux prévalant dans les villes d'Amherstburg et de Sandwich étaient aussi plus élevés que dans la campagne environnante. Ceci dit, à Ottawa comme dans tous ces cantons ruraux, nous retrouvons toujours les mêmes disparités de taux d'un groupe ethnique à l'autre. Ces unions ne tenaient pas seulement à l'attrait réciproque des personnes concernées et à leur capacité de faire face aux préjugés et aux interdits, mais elles étaient aussi le fruit des rapports intercommunautaires puisque certains groupes, vu leur faible dimension, devaient se résigner à recruter des conjoints en dehors de leur cercle restreint. Ainsi, partout, qu'on se place du côté des partenaires masculins ou féminins, les groupes ethniques les moins nombreux, en l'occurrence les Écossais, les Anglais et les Allemands, étaient ceux qui possédaient les taux les plus élevés de mariages entre personnes d'origine ethnique et d'appartenance religieuse différentes. Mais ce facteur ne suffit pas à rendre compte de l'ampleur des écarts de taux qui existaient, par exemple, entre les Irlandais et les Canadiens français. Il n'explique pas non plus les disparités qui subsistent une fois que les taux des Écossais, des Anglais et des Allemands sont calculés ensemble, puisque, dans ce cas, le nombre total de leurs couples est de 1001 , alors que celui des Irlandais est de 1078 et celui des Canadiens français de 1 179. Ainsi comptés, en utilisant le nombre de partenaires masculins engagés dans ces unions, les taux de ces trois groupes de dimension comparable différaient encore considérablement les uns des autres: $43,5 \%$ dans le premier, 20,6\% dans le deuxième et 
6,5\% dans le troisième. Cela signifie que l'ethnicité et la religion représentaient des barrières importantes à cet égard.

Le taux d'exogamie des Irlandais protestants l'emportait de beaucoup sur celui des Irlandais catholiques: $36,5 \%$ chez les premiers et $10 \%$ chez les seconds. Dans l'ensemble, les maris catholiques représentaient $59 \%$ des époux, mais leur contribution aux unions interethniques n'en totalisait que $26 \%$. À plus forte raison, en était-il ainsi des alliances interconfessionnelles, strictement réprimées par les clergés, dont le pourcentage n'était que de $15 \%$. Il va sans dire que, même si les Églises n'interdisaient pas formellement les mariages interethniques, les familles elles-mêmes y mettaient des obstacles, dont l'efficacité variait d'une croyance à une autre. Dans ce camp, les catholiques et, surtout, les Canadiens français étaient ceux qui pratiquaient davantage l'isolationnisme culturel. C'est aussi un fait qu'Yves Frenette note à propos des Canadiens français de Lewiston, Maine ${ }^{34}$ : en 1872 , écrit-il, leur taux d'exogamie était de seulement 2,3\%.

\footnotetext{
${ }^{34}$ Yves Frenette, Genèse d'une communauté canadienne-française en NouvelleAngleterre: Lewiston, Maine, 1800-1880. Thèse de Ph. D., Université Laval, 1988, p. 333, 333a, 334.
} 
TABLEAU 13

Époux engagés dans des mariages exogames

selon l'origine ethnique et la religion à Ottawa en 1871.

\begin{tabular}{|c|c|c|c|c|}
\hline & $\begin{array}{c}\text { inter- } \\
\text { ethniques }\end{array}$ & $\begin{array}{c}\text { inter- } \\
\text { confessionnels }\end{array}$ & $\begin{array}{l}\text { les deux } \\
\text { à la fois }\end{array}$ & total \\
\hline \multicolumn{5}{|l|}{ Écossais } \\
\hline couples (nombre) & 341 & 341 & 341 & 341 \\
\hline époux (nombre) & 120 & 17 & 26 & 163 \\
\hline$\%$ & 35,2 & 5,0 & 7,9 & 47,8 \\
\hline \multicolumn{5}{|l|}{ Anglais } \\
\hline couples (nombre) & 628 & 628 & 628 & 628 \\
\hline époux (nombre) & 183 & 15 & 54 & 252 \\
\hline$\%$ & 29,1 & 2,4 & 8,6 & 40,1 \\
\hline \multicolumn{5}{|l|}{ Allemands } \\
\hline couples (nombre) & 32 & 32 & 32 & 32 \\
\hline époux (nombre) & 16 & 0 & 2 & 18 \\
\hline$\%$ & 50,0 & 0 & 6,2 & 56,2 \\
\hline \multicolumn{5}{|l|}{ Irlandais catholiques } \\
\hline couples (nombre) & 648 & 648 & 648 & 648 \\
\hline époux (nombre) & 50,0 & 9,0 & 6,0 & 65 \\
\hline$\%$ & 7,7 & 1,4 & 0,4 & 10 \\
\hline \multicolumn{5}{|l|}{ Irlandais protestants } \\
\hline couples (nombre) & 430 & 430 & 430 & 430 \\
\hline époux (nombre) & 100 & 35 & 22 & 157 \\
\hline$\%$ & 23,2 & 8,1 & 5,1 & 36,5 \\
\hline \multicolumn{5}{|l|}{ Anglophones } \\
\hline couples (nombre) & 2079 & 2079 & 2079 & 2079 \\
\hline époux (nombre) & 469 & 76 & 110 & 655 \\
\hline$\%$ & 22,5 & 3,6 & 5,3 & 31,5 \\
\hline \multicolumn{5}{|l|}{ Canadiens français } \\
\hline couples (nombre) & 1179 & 1179 & 1179 & 1179 \\
\hline époux engagés & 67 & 1 & 9 & 77 \\
\hline$\%$ & 5,7 & 0.08 & 0,8 & 6,5 \\
\hline \multicolumn{5}{|l|}{ Grand total } \\
\hline couples (nombre) & 3258 & 3258 & 3258 & 3258 \\
\hline époux engagés & 536 & 77 & 119 & 732 \\
\hline$\%$ & 16,4 & 2,4 & 3,7 & 22,5 \\
\hline
\end{tabular}

Source: APC, Recensement nominatif d'Ottawa de 1871, bobines 10013 , 10014 et 10015 . 
Parmi les 3258 couples d'Ottawa, il y avait eu 732 mariages exogames, dont 655 interethniques et 196 interconfessionnels, contractés par un nombre égal de maris et d'épouses. Mais la répartition entre les groupes ethniques et confessionnels des maris et des épouses engagés dans ces mariages n'était pas la même. Ainsi, chez les Anglais, le nombre de maris dans ces unions se chiffrait à 252 , alors que le nombre d'épouses de même origine n'était que de 180. Par contre, chez les Irlandais, le nombre de maris n'était que de 222, alors que le nombre d'épouses s'élevait à 313. Aussi les taux de mariages exogames variaient-ils en conséquence: $40,1 \%$ parmi les époux anglais et 28,6\% chez les épouses de même origine contre un taux de 20,6\% parmi les maris irlandais et de 29,0 chez les épouses de même origine. Il y avait donc des groupes ethniques qui avaient été à court d'épouses et des groupes qui en avaient un surplus. Par exemple, le nombre d'Anglais, d'Allemands et de Canadiens français qui avaient contracté des unions interethniques était de 347 maris et de 246 conjointes, soit une différence de 101. De l'autre côté, les Écossais et les Irlandais avaient eu un surplus de 101 épouses. Les Irlandais, surtout les catholiques, avaient été les premiers pourvoyeurs d'épouses, ce qui, pour plusieurs d'entre eux, avait été une source de confirmation, voire de promotion, sociale. 


\section{DiSPARITÉS SOCIO-ÉCONOMIQUES ET CULTURELLES À OTTAWA EN 1871}

TABLEAU 14

Épouses engagées dans des mariages exogames selon l'origine ethnique et la religion à Ottawa en 1871.

\begin{tabular}{lccc}
\hline $\begin{array}{c}\text { inter- } \\
\text { ethniques }\end{array}$ & $\begin{array}{c}\text { inter- } \\
\text { confessionnels }\end{array}$ & les deux à la fois & total \\
Écossaises & &
\end{tabular}

couples (nombre)

$\begin{array}{cccc}341 & 341 & 341 & 341 \\ 130 & 17 & 26 & 173 \\ 38,1 & 5,0 & 7,6 & 50,7\end{array}$

Anglaises

couples (nombre)

628

628

628

628

épouses (nombre)

$\%$

22,9

2,4

3,3

28,6

Allemandes

couples (nombre)

32

9

32

32

32

épouses (nombre)

28,1

0

2

11

$\%$

0

6,2

34,3

Irlandaises catholiques

couples (nombre)

$\begin{array}{cccc}648 & 648 & 648 & 648 \\ 76 & 22 & 45 & 143 \\ 11,7 & 3,4 & 6,9 & 22,1\end{array}$

Irlandaises protestantes

couples (nombre)

épouses (nombre)

$\%$

Anglophones

couples (nombre)

2079

2079

2079

2079

épouses (nombre)

494

76

107

677

23,8

3,6

5,1

32,6

Canadiennes françaises

couples (nombre)

1179

1179

1179

1179

épouses (nombre)

42

1

12

55

$\%$

$3,6 \quad 0.08$

1,6

4,7

Grand total

couples (nombre)

épouses (nombre)

$\begin{array}{cccc}3258 & 3258 & 3258 & 3258 \\ 536 & 77 & 119 & 732 \\ 16,4 & 2,4 & 3,8 & 22,5\end{array}$

Source: APC, Recensement nominatif d'Ottawa de 1871, bobines 10013 , 10014 et 10015 . 
C'était davantage par les femmes que ce mouvement s'était produit. Ainsi le nombre d'épouses catholiques engagées dans des mariages interethniques était de $7,2 \%$ supérieur à celui des maris de même croyance. Dans le cas des unions interconfessionnelles, cette différence atteignait $31,1 \%$. Aussi les taux de mariages exogames chez les maris catholiques étaient inférieurs à celui des épouses catholiques, 9,3\% contre $12,5 \%$, alors que la situation contraire prévalait parmi les protestants: des taux de $41,7 \%$ chez les maris et de $37,1 \%$ chez les épouses. Néanmoins, chez les Irlandais catholiques et protestants, ces réservoirs d'épouses à marier, les taux étaient plus élevés chez les épouses que chez les maris: des taux respectifs de $10 \%$ et de $22,1 \%$ parmi les catholiques et de $36,5 \%$ et de $39,5 \%$ parmi les protestants. Chez les Canadiens français, les taux étaient de 6,5\% chez les maris et de 4,6\% chez les épouses.

Des maris et des épouses aux enfants adultes, la répartition des individus dans l'univers des croyances religieuses n'était pas tellement différente que celle de leurs parents. Disons, cependant, qu'ils étaient proportionnellement plus catholiques qu'eux et, dans le cas des jeunes Écossais, plus liés au presbytérianisme et à l'Église d'Écosse que leurs parents. Cela implique que l'Église d'Angleterre avait perdu du terrain chez les jeunes. Ajoutons que les jeunes Canadiens français, comme les Irlandais, affichaient la même loyauté au catholicisme que leurs parents. 


\section{DiSPARITÉS SOCIO-ÉCONOMIQUES ET CULTURELLES À OTTAWA EN 1871}

TABLEAU 15

Religion des enfants adultes de la famille, membres de la maisonnée, mais non chefs de maisonnée, ayant déclaré une occupation à Ottawa en 1871.

\begin{tabular}{|c|c|c|c|c|c|c|c|}
\hline & Écossais & Anglais & $\begin{array}{c}\text { Alle- } \\
\text { mands }\end{array}$ & Irlandais & $\begin{array}{l}\text { Anglo- } \\
\text { phones }\end{array}$ & $\begin{array}{c}\text { Canadiens } \\
\text { français }\end{array}$ & Total \\
\hline $\begin{array}{l}\text { Église ca } \\
\text { nombre }\end{array}$ & 15 & 10 & 1 & 257 & 283 & 332 & 615 \\
\hline$\%$ & 15,3 & 7,7 & 16,7 & 61,6 & 43,5 & 100 & 62,6 \\
\hline \multicolumn{8}{|c|}{ Église anglicane } \\
\hline$\%$ & 6,1 & 51,9 & 83,3 & 18,5 & 23,8 & 0 & 15,8 \\
\hline \multicolumn{8}{|c|}{ Église presbytérienne } \\
\hline$\%$ & 43,9 & 10,8 & 0 & 9,1 & 14,6 & 0 & 9,7 \\
\hline \multicolumn{8}{|c|}{ Église d'Écosse } \\
\hline$\%$ & 18,4 & 0,8 & 0 & 0,5 & 3,2 & 0 & 2,1 \\
\hline \multicolumn{8}{|c|}{ Église méthodiste } \\
\hline$\%$ & 10,2 & 21,7 & 0 & 8,6 & 11,4 & 0 & 7,5 \\
\hline \multicolumn{8}{|c|}{ Église baptiste } \\
\hline$\%$ & 4,1 & 2,3 & 0 & 0 & 1,1 & 0 & 0,7 \\
\hline \multicolumn{8}{|l|}{ Autres } \\
\hline$\%$ & 2,0 & 4,6 & 0 & 1,7 & 2,3 & 0 & 1,5 \\
\hline \multicolumn{8}{|l|}{ Total } \\
\hline$\%$ & 100 & 99,8 & 100 & 100 & 99,9 & 100 & 99,9 \\
\hline
\end{tabular}

Source: APC, Recensement nominatif d'Ottawa de 1871, bobines 10013 , 10014 et 10015 . 
Quant aux étrangers vivant dans les maisonnées, il faut rappeler qu'ils étaient non seulement plus âgés que ces jeunes adultes, membres de la famille, et que les domestiques, mais plus jeunes d'une décennie que les chefs de maisonnée où ils résidaient. Ils étaient aussi, beaucoup moins que ces derniers, affiliés aux Églises dominantes: 33 \% des Écossais appartenaient aux Églises presbytérienne et d'Écosse, alors que l'Église anglicane ne ralliait que $42 \%$ des Anglais. Par contre, les Irlandais catholiques représentaient, comme parmi les chefs de maisonnée, $60 \%$ des effectifs irlandais. Quant aux Canadiens français, seulement deux individus sur 248 se rattachaient à des Églises protestantes.

Au sein de la cohorte des chefs de maisonnée abritant des étrangers et de celle des étrangers eux-mêmes, quatre groupes apparaissent. D'abord, les Écossais, les Anglais et les Allemands étaient protestants dans une proportion de $95,4 \%$, alors que les étrangers qui résidaient avec eux ne l'étaient que selon un pourcentage de $81,6 \%$. Cela reflétait sans doute la position dominante de ces groupes ethniques dans l'économie, car, dans ces maisonnées, les étrangers étaient plus souvent des employés ou des apprentis. Le deuxième groupe était celui des Irlandais catholiques: ils étaient catholiques à raison de $45,4 \%$ et les étrangers qui habitaient avec eux et qui, très souvent, contribuaient au budget familial en payant pension, ne l'étaient que dans une proportion de $42,4 \%$. Les deux groupes qui donnaient l'impression d'être plus défensifs vis-à-vis des personnes d'une autre religion étaient les Irlandais protestants et les Canadiens français, puisque, dans ces deux cas, le pourcentage des étrangers de même confession religieuse que leurs hôtes était supérieur à celui de ces chefs de maisonnée. 


\section{DisPARITÉS SOCIO-ÉCONOMIQUES ET CULTURELLES À OTTAWA EN 1871}

TABLEAU 16

Religion des chefs de maisonnée avec étrangers à la maison et celle de ces étrangers ayant déclaré une occupation à Ottawa en 1871.

\begin{tabular}{|c|c|c|c|c|c|c|c|}
\hline & Écossais & Anglais & $\begin{array}{l}\text { Alle- } \\
\text { mands }\end{array}$ & Irlandais & $\begin{array}{l}\text { Anglo- } \\
\text { phones }\end{array}$ & $\begin{array}{l}\text { Canadiens } \\
\text { français }\end{array}$ & Total \\
\hline \multicolumn{8}{|c|}{ 1. Chefs de maisonnée avec étrangers à la maison } \\
\hline $\begin{array}{l}\text { nombre } \\
\text { catholiques }\end{array}$ & 51 & 74 & 6 & 99 & 230 & 98 & 328 \\
\hline nombre & 2 & 3 & 1 & 45 & 51 & 93 & 144 \\
\hline $\begin{array}{c}\% \\
\text { protestants }\end{array}$ & 3,6 & 4,0 & 16,7 & 45,4 & 22,1 & 94,9 & 47,2 \\
\hline $\begin{array}{l}\text { nombre } \\
\%\end{array}$ & $\begin{array}{r}49 \\
96,4\end{array}$ & $\begin{array}{l}71 \\
96\end{array}$ & $\begin{array}{r}5 \\
83,3\end{array}$ & $\begin{array}{r}54 \\
54,6\end{array}$ & $\begin{array}{r}179 \\
77,9\end{array}$ & $\begin{array}{r}5 \\
5,1\end{array}$ & $\begin{array}{r}184 \\
57,9\end{array}$ \\
\hline \multicolumn{8}{|c|}{ 2. Étrangers dans ces maisonnées } \\
\hline \multicolumn{8}{|l|}{$\begin{array}{l}\text { Ecossais } \\
\text { catholiques }\end{array}$} \\
\hline$\%$ & 4,8 & 9,4 & 证 & 8,7 & 7,2 & 54,5 & 12,0 \\
\hline \multicolumn{8}{|l|}{ protestants } \\
\hline $\begin{array}{l}\text { nombre } \\
\%\end{array}$ & 40 & 29 & 0 & 21 & 90 & 5 & 95 \\
\hline $\begin{array}{c}\% \\
\text { Anglais }\end{array}$ & 95,2 & 90,6 & 0 & 91,3 & 92,8 & 45,5 & 88,0 \\
\hline \multicolumn{8}{|l|}{$\begin{array}{l}\text { Anglais } \\
\text { catholiques }\end{array}$} \\
\hline nombre & 0 & 2 & 1 & 4 & 7 & 5 & 12 \\
\hline \multirow{2}{*}{\multicolumn{8}{|c|}{ protestants }} \\
\hline & & & & & & & \\
\hline nombre & 12 & 84 & 1 & 48 & 145 & 4 & 149 \\
\hline $\begin{array}{c}\% \\
\text { Allemands }\end{array}$ & 100 & 97,7 & 50,0 & 92,3 & 95,4 & 44,5 & 92,2 \\
\hline \multicolumn{8}{|l|}{ Allemands } \\
\hline nombre & 0 & 0 & 0 & 0 & 0 & & \\
\hline$\%$ & 0 & 0 & 0 & 0 & 0 & 88,8 & 66,7 \\
\hline \multicolumn{8}{|l|}{ protestants } \\
\hline $\begin{array}{l}\text { nombre } \\
\%\end{array}$ & 1 & 2 & 0 & 0 & 3 & 1 & \\
\hline$\stackrel{\%}{\%}$ & 100 & 100 & 0 & 0 & 100 & 11,2 & 33,3 \\
\hline \multicolumn{8}{|l|}{$\begin{array}{l}\text { Irlandais } \\
\text { catholiques }\end{array}$} \\
\hline nombre & 11 & 19 & 0 & 73 & 103 & 60 & 163 \\
\hline \multirow{2}{*}{\multicolumn{8}{|c|}{ protestants }} \\
\hline & & & & & & & \\
\hline $\begin{array}{l}\text { nombre } \\
\%\end{array}$ & $\begin{array}{r}18 \\
62.1\end{array}$ & $\begin{array}{r}25 \\
56,8\end{array}$ & $\begin{array}{r}4 \\
100\end{array}$ & $\begin{array}{r}53 \\
42,1\end{array}$ & $\begin{array}{r}100 \\
49,3\end{array}$ & $\begin{array}{r}5 \\
7,7\end{array}$ & $\begin{array}{r}105 \\
39,2\end{array}$ \\
\hline \multirow{2}{*}{\multicolumn{8}{|c|}{$\begin{array}{l}\text { Canadiens français } \\
\text { catholiques }\end{array}$}} \\
\hline & & & & & & & \\
\hline nombre & 3 & 8 & 0 & 11 & 22 & 224 & 246 \\
\hline & 60,0 & 100 & 0 & 100 & 91,7 & 100 & 99,2 \\
\hline \multicolumn{8}{|l|}{ protestants } \\
\hline $\begin{array}{l}\text { nor } \\
\%\end{array}$ & 2 & 0 & 0 & 0 & 2 & 0 & 2 \\
\hline & 40,0 & 0 & 0 & 0 & 8,3 & & 0,8 \\
\hline \multicolumn{8}{|l|}{$\begin{array}{l}\text { Grand total } \\
\text { catholiques }\end{array}$} \\
\hline nombre & 16 & 32 & 1 & 90 & 139 & 303 & 442 \\
\hline$\%$ & 18,0 & 18,6 & 16,7 & 42,4 & 29,0 & 95,3 & 55,4 \\
\hline $\begin{array}{l}\text { protestants } \\
\text { nombre }\end{array}$ & 73 & 140 & 5 & 122 & 340 & 15 & 355 \\
\hline$\%$ & 82,0 & 81,4 & 83,3 & 57,6 & 71,0 & 4,7 & 44,6 \\
\hline Ensemble & & & & & & & \\
\hline nomb & 89 & 172 & 6 & 212 & 479 & 318 & 797 \\
\hline$\%$ & 100 & 100 & 100 & 100 & 100 & 100 & 100 \\
\hline
\end{tabular}

Source: APC, Recensement nominatif d'Ottawa de 1871, bobines 10013 , 10014 et 10015 . 
La configuration confessionnelle des domestiques était bien différente de celle des jeunes adultes vivant à la maison avec leurs parents. Les domestiques, au nombre de 388, qui œuvraient dans les maisons des Écossais, des Anglais et des Allemands, étaient catholiques dans une proportion de $44 \%$, alors que les jeunes adultes habitant les mêmes maisonnées ne l'étaient que dans une proportion de $11 \%$. Ils se distinguaient également de leurs patrons ou de leurs patronnes, dont les effectifs catholiques se réduisaient à $12 \%$.

Nous pouvons croire que ces patronnes avaient d'abord tenté, pour satisfaire à leurs besoins en domestiques, de choisir leurs domestiques parmi des personnes de leur confessionnalité. Mais, comme elles n'en avaient trouvé que 148 de cette description, soit 14 catholiques et 134 protestantes, elles avaient été, dans un second temps, obligées d'étendre leur recrutement aux groupes ethniques qui auraient pu leur fournir les 240 manquantes. D'abord, chez les Irlandais protestants qui leur en avaient procurées 83 et, ensuite, chez les Irlandais catholiques et les Canadiens français catholiques, où elles en avaient recrutées 141 et 16 respectivement. 
DisPaRITÉS SOCIO-ÉCONOMIQUES ET CULTURELLES À OTTAWA EN 1871

TABLEAU 17

Religion des domestiques et celle de leurs employeurs à Ottawa en 1871.

\begin{tabular}{|c|c|c|c|c|c|c|c|}
\hline & Écossais & Anglais & $\begin{array}{l}\text { Alle- } \\
\text { mands }\end{array}$ & Irlandais & $\begin{array}{l}\text { Anglo- } \\
\text { phones }\end{array}$ & $\begin{array}{l}\text { Canadiens } \\
\text { français }\end{array}$ & Total \\
\hline \multicolumn{8}{|c|}{$\begin{array}{l}\text { Religion des domestiques selon l'origine ethnique } \\
\text { des chefs de maisonnée qui les employaient } \\
\text { catholiques }\end{array}$} \\
\hline nombre & 56 & 110 & 5 & 157 & 328 & 204 & 532 \\
\hline$\%$ & 44,4 & 42,8 & 100 & 63,0 & 51,5 & 96,7 & 62,7 \\
\hline \multicolumn{8}{|l|}{ protestants } \\
\hline nombre & 70 & 147 & 0 & 92 & 309 & 7 & 316 \\
\hline$\%$ & 55,6 & 57,2 & 0 & 37,0 & 48,5 & 3,3 & 37,3 \\
\hline \multicolumn{8}{|l|}{ Total } \\
\hline nombre & 126 & 257 & 5 & 249 & 637 & 211 & 848 \\
\hline$\%$ & 100 & 100 & 100 & 100 & 100 & 100 & 100 \\
\hline \multicolumn{8}{|c|}{$\begin{array}{l}\text { Domestiques selon leur propre appartenance ethnique } \\
\text { catholiques }\end{array}$} \\
\hline nombre & 5 & 9 & 0 & 298 & 312 & 220 & 532 \\
\hline$\%$ & 7,8 & 11,2 & 0 & 63,0 & 50,2 & 96,9 & 62,7 \\
\hline \multicolumn{8}{|l|}{ protestants } \\
\hline nombre & 59 & 71 & 4 & 175 & 309 & 7 & 316 \\
\hline$\%$ & 92,2 & 88,8 & 100 & 37,0 & 49,8 & 3,1 & 37,3 \\
\hline \multicolumn{8}{|l|}{ Total } \\
\hline nombre & 64 & 80 & 4 & 473 & 621 & 227 & 848 \\
\hline$\%$ & 100 & 100 & 100 & 100 & 100 & 100 & 100 \\
\hline
\end{tabular}

Source: APC, Recensement nominatif d'Ottawa de 1871, bobines 10013 , 10014 et 10015 .

La société d'Ottawa, bien qu'assez rigidement structurée sur les plans ethnique et confessionnel, n'était quand même pas formée de communautés tout à fait autonomes et isolées les unes des autres. Déjà, par le biais des mariages exogames, par la présence des étrangers dans les maisonnées et par le recours aux services de domestiques, les communautés qui la constituaient avaient eu des contacts entre elles. Il n'en reste pas moins qu'il faut souligner à ces égards l'exceptionnelle intensité du repli culturel de la communauté canadienne-française, si bien prise en charge par son clergé. Dans un tel contexte, l'école pour tous, telle qu'envisagée par Ryerson, aurait pu créer un 
lieu privilégié pour tempérer davantage les sectarismes ethnique et religieux et stimuler le sens de la citoyenneté.

\section{III - AlphabÉtisation et fréQuentation scolaire}

Le type d'écoles établi par Ryerson parut d'abord d'autant plus acceptable aux Canadiens français ordinaires que, dès 1851, lui-même avait reconnu les droits scolaires des Canadiens français, des Allemands et des Afro-Américains. Mais c'était compter sans les évêques catholiques militants qui, utilisant l'arme du péché mortel, menèrent une guerre sans merci contre les "infernales écoles mixtes", des "écoles sans Dieu», disaient-ils, et vouées «à l'immoralité » si elles admettaient des filles et des garçons dans les mêmes classes. C'était aussi ne pas tenir compte du sectarisme de nombre de commissaires d'école protestants qui, par leurs actions, servirent les visées isolationnistes du clergé catholique. Toujours est-il que le mouvement vers les écoles séparées ne cessa de progresser par la suite. Ainsi, de 1851 à 1867 , le nombre de ces écoles passa de 16 à $161^{35}$. Alors que, pour les Irlandais catholiques, l'école séparée était un moyen d'affirmer leur caractère propre par rapport aux protestants, elle constituait, pour ses promoteurs canadiens-français, un instrument de protection contre les cultures anglo-protestantes et anglo-catholiques.

Aussi les évêques du Canada-Est qui présidèrent au développement des institutions catholiques en Ontario jusqu'à l'érection de la province ecclésiastique de Toronto en 1870, s'empressèrent-ils d'accéder aux demandes d'institutions faites par les oblats pour satisfaire aux besoins d'une population pauvre et fortement divisée. Dès 1845, avant la création du diocèse d'Ottawa, les sœurs grises se rendirent à l'appel du curé Adrien Telmon. Pendant le quart de siècle suivant, la communauté d'Ottawa fonda des écoles élémentaires, deux académies, un hôpital qui

${ }^{35}$ Cette question a été longuement discutée par Choquette, op. cit., p. 281-312. 
devint l'Hôpital général, une maison pour filles-mères et leurs filles, qu'elles qualifèrent de "pénitentes", ainsi que deux orphelinats, l'un pour les Canadiennes françaises et l'autre pour les Irlandaises. En 1868, les dames de la Congrégation arrivèrent à Ottawa et établirent un couvent au cour de la haute ville. En 1871, il abritait sept religieuses âgées de 27 ans en moyenne, trois novices âgées de 18 ans, ainsi que 32 pensionnaires. Quatre des religieuses et toutes les novices étaient nées au Québec. Trois des religieuses étaient canadiennes-françaises, ainsi que les novices. Toutes ces institutions, excepté l'asile Saint-Patrice et, peut-être, l'école des dames de la Congrégation, la supérieure étant une Irlandaise d'originaire américaine, s'adressaient d'abord aux Canadiennes françaises et, exclusivement, aux femmes.

Il va sans dire que, pendant ces années, la communauté des sœurs grises d'Ottawa crût en nombre et en importance. Même si, en cours de route, elle fut en mesure de se délester de personnel religieux afin d'aller fonder de nouveaux établissements dans l'Est ontarien et aux États-Unis, le nombre de ses religieuses dans la ville s'élevait à 93, de novices à 24 , de domestiques à son service à 19 et de résidentes à 158 en 1871. Le Canada-Est était, par une marge considérable, le lieu de naissance de la grande majorité des religieuses et des novices. Quant aux résidentes, c'est-à-dire aux femmes âgées et handicapées, aux orphelines, aux «pénitentes » et aux pensionnaires, elles étaient nées au Canada-Est et au Canada-Ouest dans une proportion de $61 \%$. Parmi les religieuses et les novices, le pourcentage des Canadiennes françaises était également fort élevé, soit de $72 \%$, alors que les personnes qu'elles hébergeaient ou traitaient, étaient réparties beaucoup plus également entre les Canadiennes françaises et les Irlandaises. Si on exclut l'asile Saint-Patrice, l'une des deux maisons à direction irlandaise, la part des Québécois et des Canadiens français était encore plus élevée. Dans ces institutions 
dominées par des Canadiennes françaises et des Françaises, le nombre de religieuses irlandaises se chiffrait à 15 , celui des novices et des résidentes de même origine à 4 et à 28 respectivement, soit un pourcentage de $17 \%$ pour les religieuses et les novices, et de $25 \%$ pour les résidentes.

TABLEAU 18

Sœurs grises à Ottawa en 1871 .

\begin{tabular}{|c|c|c|c|c|c|}
\hline & religieuses & novices & total & domestiques & résidentes \\
\hline Nombre total & 93 & 24 & 117 & 19 & 158 \\
\hline Âge moyen & 30 & 20 & 28 & 26 & 18 \\
\hline \multicolumn{6}{|c|}{ Lieu de naissance } \\
\hline nombre & 61 & 19 & 80 & 8 & 57 \\
\hline$\%$ & 65,6 & 79,2 & 68,4 & 42,1 & 36,1 \\
\hline \multicolumn{6}{|c|}{ nées en Ontario } \\
\hline nombre & 11 & 1 & 12 & 2 & 40 \\
\hline$\%$ & 11,8 & 4,2 & 10,2 & 10,5 & 25,3 \\
\hline \multicolumn{6}{|l|}{ nées ailleurs } \\
\hline nombre & 21 & 4 & 25 & 9 & 61 \\
\hline$\%$ & 22,6 & 16,6 & 21,4 & 47,4 & 38,6 \\
\hline \multicolumn{6}{|c|}{ Origine ethnique } \\
\hline \multicolumn{6}{|c|}{ Canadiennes françaises } \\
\hline nombre & 64 & 20 & 84 & 8 & 71 \\
\hline$\%$ & 68,8 & 83,3 & 71,8 & 42,1 & 44,9 \\
\hline \multicolumn{6}{|l|}{ Françaises } \\
\hline nombre & 2 & 0 & 0 & 0 & 0 \\
\hline$\%$ & 2,1 & 0 & 0 & 0 & 0 \\
\hline \multicolumn{6}{|l|}{ Irlandaises } \\
\hline nombre & 19 & 4 & 23 & 9 & 63 \\
\hline$\%$ & 20,4 & 16,7 & 19,6 & 47,4 & 39,9 \\
\hline \multicolumn{6}{|l|}{ Autres } \\
\hline nombre & 8 & 0 & 8 & 2 & 24 \\
\hline$\%$ & 8,6 & 0 & 6,8 & 10,5 & 15,2 \\
\hline
\end{tabular}

Source: APC, Recensement nominatif d'Ottawa de 1871, bobines 10013 , 10014 et 10015 .

Dans les maisons à direction francophone, les pressions et l'atmosphère favorisaient d'autant plus le bilinguisme que c'est dans la maison-mère, où la sœur Élizabeth Bruyère 
était supérieure, que se trouvaient les novices. Nous ne saurions, pour autant, en conclure que la minorité anglophone se prêtait de bon cœur à l'apprentissage du français.

Dans ce groupe, 41 religieuses étaient affectées aux institutions catholiques vouées à la charité. Presque la moitié d'entre elles étaient nées au Canada-Est et plus de la moitié étaient canadiennes-françaises. Elles s'occupaient, entre autres, de 138 résidentes dont l'âge moyen était de 18 ans et elles apprenaient à lire et à écrire aux 73 enfants d'âge scolaire qui faisaient partie de ce groupe.

À côté de ce réseau impressionnant, se trouvaient deux petites institutions soutenues par l'Église d'Angleterre, soit un refuge pour femmes et un orphelinat pour garçons et filles. Les deux directrices étaient laïques et relevaient de l'Église d'Angleterre. Les 31 résidents étaient des femmes et des enfants des deux sexes âgés de 10 ans en moyenne. Il s'agissait de personnes d'appartenances ethniques et confessionnelles diverses.

À part les filles alphabétisées dans les institutions catholiques de charité, il y avait les écolières qui fréquentaient les écoles et les académies des sœurs grises, ainsi que le couvent des dames de la Congrégation. Nous connaissons le nombre de pensionnaires, mais, le plus souvent, nous ignorons le nombre des autres. Ainsi, le couvent Notre-Dame-du-Sacré-Cœur, où le père Henri Tabaret était supérieur, accueillait 216 élèves, dont seulement 18 pensionnaires. Ces écolières catholiques se répartissaient inégalement entre francophones et anglophones. En 1876, les sœurs grises instruisaient 410 francophones et 240 anglophones dans leurs écoles ${ }^{36}$. Il est évident que les filles anglophones catholiques étaient si fortement sousreprésentées dans ce milieu qu'un grand nombre d'entre elles étaient scolarisées dans les écoles publiques.

${ }^{36}$ Robert Choquette, op. cit., p. 300. 
Il faut dire que les communautés religieuses n'étaient pas entièrement libres de leurs mouvements puisque, depuis la création du diocèse, elles relevaient de l'évêque d'Ottawa qui, à son tour, dépendait de l'archevêque de Québec. M ${ }^{\text {gr }}$ Guigues, originaire de France, était assisté d'un prêtre canadien-français, vicaire-général et administrateur du diocèse, lui-même entouré de deux Irlandais et d'un Canadien français. Comme ils devaient tous veiller au recrutement sacerdotal, ils n'avaient pas tardé à fonder un collège qui se vit octroyer une charte universitaire en 1866, en tant qu'institution catholique particulièrement destinée aux francophones, mais desservant aussi les anglophones ${ }^{37}$. Dès 1849 , on lui avait annexé l'école élémentaire des garçons de l'abbé Mignault, institution qui, en 1864, passa aux mains des frères des Écoles chrétiennes avec ses $\mathbf{5 5 0}$ élèves. En 1871, le collège d'Ottawa était dirigé par un prêtre de France et son enseignement était dispensé par 11 prêtres, dont cinq Français, un Canadien français et trois Irlandais. Ceux qui se préparaient à la prêtrise étaient au nombre de 17, dont 13 Canadiens français nés au Québec, 2 Français et 2 Irlandais. Il y avait en outre 33 étudiants: 18 étaient nés au Québec, mais 16 étaient Irlandais et 13 Canadiens français. Il semble qu'il y avait en plus une centaine d'élèves externes parmi lesquels les Irlandais étaient les plus nombreux. On comprend que le collège d'Ottawa soit devenu un des hauts lieux de dissension linguistique. Le problème était de taille puisqu'il s'agissait en fin de compte de pourvoir aux besoins multiples de deux communautés ethniques profondément divisées à l'intérieur du diocèse. En effet, l'une de ces communautés était en grande expansion démographique et relativement bien ravitaillée par le Canada-Est en candidats pour les fonctions cléricales et autres, tandis que l'autre était, à l'échelle du diocèse, en perte de vitesse et éprouvait de

${ }^{37}$ Roger Guindon, op. cit., p. 47. 
grandes difficultés à recruter les effectifs nécessaires à son développement. Tout ceci explique que de nombreux parents catholiques irlandais, faisant fi des censures ecclésiastiques, envoyaient leurs enfants dans les écoles et les collèges publics. Pour les écoles publiques, le recensement de 1871 fournit les noms de 43 instituteurs laïques, dont 21 femmes, 20 Irlandais, 13 Anglais et 10 Écossais. Parmi eux, on dénombre 8 catholiques, 17 anglicans, 11 presbytériens et 7 autres de croyances diverses.

Il y avait donc à Ottawa un réseau d'écoles relativement bien développé et aisément accessible. Les individus, selon leur âge, leur milieu social, leur religion et leur lieu de naissance, avaient été plus ou moins touchés par la révolution scolaire amorcée vers 1840 dans les Canadas. Il est vrai que les chefs de maisonnée écossais, anglais et allemands nés en Ontario étaient moins alphabétisés que ceux nés ailleurs; par contre, les Irlandais et les Canadiens français l'étaient beaucoup plus. Les taux d'analphabétisme étaient de 3,3\% chez ceux nés en Ontario et de $2 \%$ chez ceux nés ailleurs pour les premiers, de $4,9 \%$ et de $13,7 \%$ respectivement pour les Irlandais et de $36,9 \%$ et de $53,9 \%$ respectivement pour les Canadiens français. Dans l'ensemble, cependant, il existait des différences très nettes, d'une part entre les Irlandais et les autres anglophones et, d'autre part, entre les Canadiens français et tous les autres. En effet, les taux moyens d'analphabétisme étaient de 2,2\% chez les Écossais, les Anglais et les Allemands, de 12,3\% chez les Irlandais et de 52,7\% chez les Canadiens français.

Ces écarts énormes tenaient, pour une bonne part, aux différences entre catholiques et protestants et au poids relatif des classes populaires dans chacune de ces communautés. Ainsi, seulement 2,6\% des protestants ne savaient ni lire ni écrire, alors que $39,4 \%$ des catholiques se trouvaient dans la même position. Mais cela n'explique pas tout puisque le taux d'analphabétisme des Irlandais catholiques se 
situait à $18,3 \%$, alors que celui des Canadiens français était de $52,7 \%$. Il ne fait pas de doute que l'héritage culturel des immigrants francophones venus du Canada-Est était bien différent de celui des immigrants catholiques venus d'Irlande et des protestants venus des îles Britanniques. En effet, le taux d'analphabétisme des Irlandais catholiques, bien que cinq fois plus élevé que celui des Irlandais protestants, était néanmoins trois fois moindre que celui des Canadiens français.

TABLEAU 19

Taux d'analphabétisme des chefs de maisonnée âgés de plus de 20 ans dans la ville d'Ottawa en 1871.

\begin{tabular}{|c|c|c|c|c|c|c|c|}
\hline & Écossais & Anglais & $\begin{array}{l}\text { Alle- } \\
\text { mands }\end{array}$ & Irlandais & $\begin{array}{l}\text { Anglo- } \\
\text { phones }\end{array}$ & $\begin{array}{c}\text { Canadiens } \\
\text { français }\end{array}$ & is Total \\
\hline \multicolumn{8}{|l|}{ Chefs de maisonnée } \\
\hline ne sait lire & 4 & 17 & 2 & 140 & 163 & 667 & 830 \\
\hline$\%$ & 1,0 & 2,3 & 5,5 & 9,9 & 6,3 & 49,7 & 21,0 \\
\hline ne sait écrire & 6 & 21 & 3 & 210 & 240 & 749 & 989 \\
\hline$\%$ & 1,5 & 2,8 & 8,3 & 14,8 & 9,2 & 55,8 & 24,3 \\
\hline \multicolumn{8}{|l|}{$\begin{array}{l}\text { Nés en Ontario } \\
\text { chefs de maisonnée }\end{array}$} \\
\hline nombre & 86 & 103 & 9 & 222 & 420 & 92 & 512 \\
\hline ne sait lire (nombre) & 2 & 3 & 1 & 8 & 14 & 30 & 44 \\
\hline$\%$ & 2,3 & 2,9 & 11,1 & 3,6 & 3,3 & 32,6 & 8,6 \\
\hline ne sait écrire (nombre) & 2 & 4 & 1 & 14 & 21 & 38 & 59 \\
\hline$\%$ & 2,3 & 3,9 & 11,1 & 6,3 & 5,0 & 41,3 & 11,5 \\
\hline \multicolumn{8}{|l|}{$\begin{array}{l}\text { Nés ailleurs } \\
\text { chefs de maisonnée }\end{array}$} \\
\hline nombre & 310 & 641 & 27 & 1197 & 2175 & 1250 & 3425 \\
\hline ne sait lire (nombre) & 2 & 14 & 1 & 132 & 149 & 637 & 786 \\
\hline$\%$ & 0,6 & 2,2 & 3,7 & 11,0 & 6,8 & 51,0 & 22,9 \\
\hline ne sait écrire (nombre) & 4 & 17 & 2 & 196 & 219 & 711 & 930 \\
\hline$\%$ & 1,3 & 2,6 & 7,4 & 16,4 & 10,1 & 56,9 & 27,1 \\
\hline
\end{tabular}

Source: APC, Recensement nominatif d'Ottawa de 1871, bobines 10013 , 10014 et 10015 .

En voyant ces chiffres, il y a lieu de s'interroger sur la pertinence des affirmations avancées par Cross sur le ni- 
veau désespérant d'alphabétisation des Irlandais et sur leurs «feelings » à l'époque de la guerre des Shiners et des épidémies de choléra de 1832 et de 1834 :

There were some Irishmen who had talent, education, and the potential for leadership [...]. No records exist to indicate the feelings of the Irish Lower Town residents - they were not a literate people ${ }^{38}$.

En effet, si cela était vrai, comment pourrait-on expliquer que les Irlandais, particulièrement les catholiques, auraient pu atteindre le niveau d'alphabétisme qu'ils avaient acquis en 1871 sans avoir reçu, depuis 1840, de traitement spécial à cet égard de la part de l'État et de l'Église catholique? D'ailleurs, nous savons que tous les Irlandais n'étaient pas catholiques et que $44,3 \%$ des Irlandais catholiques résidaient en dehors des quartiers Ottawa-By,

D'autant plus que les différences entre les chefs de maisonnée et les épouses n'étaient pas tellement importantes. Cela dans tous les groupes ethniques, y compris les Irlandais. Cet écart n'était que de $1,1 \%$ parmi les anglophones et de $4,1 \%$ parmi les Canadiens français. Par contre, dans tous les groupes, sans doute parce qu'elles étaient plus jeunes que les chefs de maisonnée, les épouses nées en Ontario étaient, par une marge significative, plus alphabétisées que celles nées ailleurs : 9\% parmi les anglophones et $14 \%$ chez les Canadiennes françaises. Enfin, les distinctions selon l'appartenance religieuse, culturelle et économique étaient encore énormes. Les protestantes étaient analphabètes dans une proportion de $2,9 \%$ et les catholiques de $37,7 \%$; les Irlandaises protestantes l'étaient dans une proportion de $3,2 \%$ et les Irlandaises catholiques de $18,1 \%$. Le niveau d'analphabétisme des Canadiennes françaises se situait à $42,8 \%$.

${ }^{38}$ Michael Cross, op. cit., "The Shiner's War: Social Violence in the Ottawa Valley in the 1830 s", CHR, 54, 1973, p. 8. 
TABLEAU 20

Taux d'analphabétisme des épouses

âgées de plus de 20 ans à Ottawa en 1871.

\begin{tabular}{|c|c|c|c|c|c|c|c|}
\hline & Écossais & Anglais & $\begin{array}{l}\text { Alle- } \\
\text { mands }\end{array}$ & Irlandais & $\begin{array}{l}\text { Anglo- } \\
\text { phones }\end{array}$ & $\begin{array}{c}\text { Canadiens } \\
\text { français }\end{array}$ & s Total \\
\hline \multicolumn{8}{|l|}{ Épouses } \\
\hline nombre & 332 & 617 & 35 & 953 & 1937 & 1113 & 3050 \\
\hline ne sait lire (nombre) & 4 & 25 & 2 & 107 & 138 & 476 & 614 \\
\hline$\%$ & 1,2 & 4,0 & 5,7 & 11,2 & 7,1 & 42,8 & 20,1 \\
\hline ne sait écrire (nombre) & 6 & 40 & 6 & 194 & 246 & 606 & 852 \\
\hline$\%$ & 1,8 & 6,5 & 17,1 & 20,3 & 12,7 & 54,4 & 27,9 \\
\hline \multicolumn{8}{|l|}{ Nées en Ontario } \\
\hline nombre & 96 & 145 & 8 & 260 & 509 & 114 & 623 \\
\hline ne sait lire (nombre) & 1 & 4 & 0 & 7 & 12 & 34 & 46 \\
\hline$\%$ & 1,0 & 2,7 & & 2,7 & 2,3 & 29,8 & 7,4 \\
\hline ne sait écrire (nombre) & 1 & 6 & 0 & 18 & 25 & 49 & 74 \\
\hline$\%$ & 1,0 & 4,1 & & 6,9 & 4,9 & 42,9 & 11,9 \\
\hline \multicolumn{8}{|l|}{ Nées ailleurs } \\
\hline nombre & 236 & 472 & 27 & 693 & 1428 & 999 & 2427 \\
\hline ne sait lire (nombre) & 3 & 21 & 2 & 100 & 126 & 442 & 568 \\
\hline$\%$ & 1,3 & 4,4 & 7,4 & 14,4 & 8,8 & 44,2 & 23,4 \\
\hline ne sait écrire (nombre) & 5 & 34 & 6 & 176 & 221 & 557 & 774 \\
\hline$\%$ & 2,1 & 7,2 & 22,2 & 25,4 & 15,5 & 57,2 & 31,9 \\
\hline
\end{tabular}

Source: APC, Recensement nominatif d'Ottawa de 1871, bobines 10 013, 10014 et 10015 .

Comme la révolution de la scolarisation était en marche depuis près de trois décennies, il allait de soi que les jeunes adultes vivant dans les maisonnées et ayant déclaré des occupations soient substantiellement plus alphabétisés que leurs parents. Ainsi, le taux d'analphabétisme déclina de $7,8 \%$, qu'il était chez les chefs de maisonnée anglophones, à $1,9 \%$ chez ces jeunes adultes. Parmi les Canadiens français, la tendance fut la même, soit une chute de $52,7 \%$ à $29,7 \%$. Étant donné que les anglophones étaient déjà presque complètement alphabétisés, il n'est pas surprenant de constater que l'écart entre ceux nés au Canada-Ouest et les autres ait été extrêmement faible: des taux respectifs de $1,7 \%$ et de $2,0 \%$. Chez les Canadiens français, la transfor- 
mation avait été remarquable puisque ceux nés au CanadaOuest n'étaient analphabètes que dans une proportion de $7,9 \%$, alors que ceux nés au Canada-Est l'étaient dans une proportion de $39,7 \%$. Cette mutation n'avait pas contribué à éliminer entièrement les contrastes entre les Irlandais catholiques et les Irlandais protestants puisque 5,1\% des premiers ne savaient ni lire, ni écrire, alors que les seconds étaient maintenant tout à fait alphabétisés.

\section{TABLEAU 21}

Taux d'analphabétisme des enfants adultes de plus de 20 ans, vivant dans les maisonnées et ayant déclaré une occupation à Ottawa en 1871 .

\begin{tabular}{|c|c|c|c|c|c|c|c|}
\hline & Écossais & Anglais & $\begin{array}{l}\text { Alle- } \\
\text { mands }\end{array}$ & Irlandais & $\begin{array}{l}\text { Anglo- } \\
\text { phones }\end{array}$ & $\begin{array}{c}\text { Canadiens } \\
\text { français }\end{array}$ & Total \\
\hline \multicolumn{8}{|l|}{ Enfants adultes } \\
\hline nombre & 73 & 71 & 3 & 201 & 348 & 121 & 469 \\
\hline ne sait lire (nombre) & 0 & 0 & 0 & 6 & 6 & 33 & 39 \\
\hline$\%$ & & & & 3,0 & 1,7 & 27,3 & 8,3 \\
\hline ne sait écrire (nombre) & 0 & 0 & 0 & 7 & 7 & 39 & 46 \\
\hline$\%$ & & & & 3,5 & 2,0 & 32,2 & 9,8 \\
\hline \multicolumn{8}{|l|}{ Nés en Ontario } \\
\hline nombre & 46 & 27 & 2 & 100 & 175 & 38 & 213 \\
\hline ne sait lire (nombre) & 0 & 0 & 0 & 3 & 3 & 3 & 6 \\
\hline$\%$ & & & & 3,0 & 1,7 & 7,9 & 2,8 \\
\hline ne sait écrire (nombre) & 0 & 0 & 0 & 3 & 3 & 3 & 6 \\
\hline$\%$ & & & & 3,0 & 1,7 & 7,9 & 2,8 \\
\hline \multicolumn{8}{|l|}{ Nés ailleurs } \\
\hline nombre & 27 & 44 & 1 & 101 & 173 & 83 & 256 \\
\hline ne sait lire (nombre) & 0 & 0 & 0 & 3 & 3 & 30 & 33 \\
\hline$\%$ & & & & 3,0 & 1,7 & 36,1 & 12,9 \\
\hline ne sait écrire (nombre) & 0 & 0 & 0 & 4 & 4 & 36 & 40 \\
\hline$\%$ & & & & 4,0 & 2,3 & 43,4 & 15,6 \\
\hline
\end{tabular}

Source : APC, Recensement nominatif d'Ottawa de 1871, bobines 10013 , 10014 et 10015 .

Quant aux étrangers résidant dans les maisonnées ou les hôtels à bon marché, ils ne faisaient que reproduire les différences habituelles entre les groupes ethniques. Le taux 
d'analphabétisme des anglophones d'âge comparable était de $1,8 \%$ et celui des Canadiens français de $16,3 \%$. Parmi les individus nés en Ontario, les anglophones savaient tous lire et écrire, alors que les Canadiens français, avec un taux de $26,2 \%$, étaient moins alphabétisés que ceux nés au Québec. Enfin, les disparités entre protestants et catholiques étaient bien marquées: $1,0 \%$ chez les premiers et $18,5 \%$ chez les seconds.

Pour conclure, disons que les domestiques étaient, par une marge considérable, moins alphabétisés que les jeunes adultes qui habitaient encore avec leurs parents : $4,4 \%$ des domestiques d'origine écossaise, anglaise et allemande, $9,5 \%$ des domestiques d'origine irlandaise et $42,8 \%$ de ceux d'origine canadienne-française étaient analphabètes. Parmi les jeunes adultes, les taux étaient les suivants: aucun chez les premiers, $3,2 \%$ chez les deuxièmes et $29,7 \%$ chez les troisièmes.

Il parait donc que, des parents aux enfants adultes et aux enfants d'âge scolaire, la fréquentation des écoles, s'était constamment accrue, sans que les disparités originelles selon l'origine ethnique, la religion et le lieu de naissance, soient dissipées pour autant. Ainsi, en 1871, les taux de fréquentation scolaire de tous les groupes ethniques étaient, excepté chez les Écossais, les Anglais et les Allemands, plus élevés parmi les Canadiens français et les Irlandais nés en Ontario que parmi ceux nés ailleurs. Entre les protestants et les catholiques, les écarts étaient également manifestes, soit $21,9 \%$ de plus chez les premiers que chez les seconds. Ils étaient d'ailleurs plus marqués entre les Canadiens français et les anglophones qu'entre ces derniers, soit de $38,1 \%$.

L'ampleur de ces différences est d'autant plus surprenante que le clergé catholique avait été capable d'édifier en moins de trois décennies un appareil institutionnel plus considérable que celui érigé par l'État pour les écoles pu- 


\section{DisPARITÉS SOCIO-ÉCONOMIQUES ET CULTURELLES À OTTAWA EN 1871}

bliques. Ce clergé avait pu, sans être uni à l'État ontarien, réaliser ce que le clergé québécois avait rêvé d'accomplir, sans y parvenir jusque-là, c'est-à-dire de mettre sur pied, à l'intention de ses fidèles, un système d'enseignement et de charité entièrement contrôlé par lui et activé par un personnel tout à fait clérical. Comme c'était l'époque où les communautés religieuses féminines, surtout au Québec, se multipliaient et recrutaient facilement des membres, la féminisation à Ottawa des effectifs enseignants francophones à l'élémentaire y atteignait un degré fort supérieur à celui qui existait partout ailleurs en Amérique du Nord, soit un taux d'environ $90 \%$. Il faut dire que cette prédominance des femmes dans un univers qui appliquait rigoureusement le principe de la ségrégation des sexes leur garantissait une suprématie numérique dans la population scolaire. Il est vrai que, à cette date, en Ontario comme au Québec depuis 1850, le pourcentage des filles dans les écoles élémentaires était devenu supérieur à celui des garçons. C'était le cas à Ottawa, en milieu anglophone, où le pourcentage des filles dans les écoles avait grimpé à 52,6\%, ce qui correspondait au taux québécois de l'époque et s'expliquait en grande partie parce que les garçons entraient plus tôt dans le monde du travail rémunéré. Mais ce l'était bien davantage chez les francophones de la ville, où, vu la ségrégation des sexes dans les écoles catholiques et la grande pauvreté des parents, la part des filles parmi les écoliers s'était même hissée à $63,2 \%$, ce qui, pourtant, n'annulait pas leur sous-scolarisation par rapport aux filles anglophones. 
TABLEAU 22

Fréquentation scolaire selon les groupes ethniques et la confession religieuse à Ottawa en 1871 .

\begin{tabular}{|c|c|c|c|c|}
\hline & $\begin{array}{l}\text { Écossais, } \\
\text { Anglais, } \\
\text { Allemands }\end{array}$ & Irlandais & $\begin{array}{l}\text { Canadiens } \\
\text { français }\end{array}$ & Total \\
\hline \multicolumn{5}{|c|}{$\begin{array}{l}\text { Familles avec enfants d'âge scolaire } \\
\text { catholiques }\end{array}$} \\
\hline nombre & 52 & 469 & 705 & 1226 \\
\hline$\%$ & 8,4 & 59,5 & 100 & 58,1 \\
\hline \multicolumn{5}{|l|}{ protestants } \\
\hline nombre & 563 & 319 & 0 & 882 \\
\hline$\%$ & 91,6 & 40,5 & & 41,9 \\
\hline Total & 615 & 788 & 705 & 2108 \\
\hline \multicolumn{5}{|l|}{ Les écoliers } \\
\hline nombre & 77 & 902 & 978 & 1957 \\
\hline$\%$ & 6,5 & 59,2 & 100 & 53,1 \\
\hline taux de fréquentation & 1,48 & 1,92 & 1,39 & 1,60 \\
\hline \multicolumn{5}{|l|}{ protestants } \\
\hline nombre & 1103 & 622 & 0 & 1725 \\
\hline$\%$ & 93,5 & 59,1 & & 46,8 \\
\hline taux de fréquentation & 1,92 & 1,93 & 1,39 & 1,75 \\
\hline \multicolumn{5}{|l|}{$\begin{array}{l}\text { Sexe des écoliers } \\
\text { filles }\end{array}$} \\
\hline nombre & 627 & 796 & 618 & 2041 \\
\hline$\%$ & 53,1 & 52,2 & 63,2 & 55,4 \\
\hline taux de fréquentation & 1,02 & 1,01 & 0,88 & 0,97 \\
\hline \multicolumn{5}{|l|}{ garçons } \\
\hline nombre & 553 & 728 & 360 & 1641 \\
\hline$\%$ & 46,9 & 47,8 & 36,8 & 44,6 \\
\hline taux de fréquentation & 0,90 & 0,92 & 0,51 & 0,78 \\
\hline \multicolumn{5}{|l|}{ Total } \\
\hline nombre & 1180 & 1524 & 978 & 3682 \\
\hline taux de fréquentation & 1,92 & 1,93 & 1,39 & 1,75 \\
\hline
\end{tabular}

Source: APC, Recensement nominatif d'Ottawa de 1871, bobines 10013 , 10014 et 10015 . 
Ainsi, au plan de l'alphabétisation, il existait des écarts bien marqués, d'une part, entre les anglophones protestants et les Irlandais catholiques, et, d'autre part, entre ceux-ci et les Canadiens français. La religion, les antécédents culturels et le degré de pauvreté des uns et des autres contribuaient à les situer dans l'une ou l'autre de ces catégories. Par contre, au plan de la scolarisation, la distinction entre Irlandais catholiques et Irlandais protestants s'était éclipsée. Défavorisés dans les écoles séparées, les Irlandais catholiques avaient fréquenté l'école publique en assez grand nombre, de sorte que la seule polarisation évidente à cet égard était celle qui existait entre les anglophones et les Canadiens français. Il est vrai que ce dernier groupe était peut-être plus pauvre et que les frères des Écoles chrétiennes n'avaient pris en charge l'éducation des garçons qu'en 1864. Il n'en demeure pas moins que l'appareil institutionnel très lourd, mis en place par le clergé catholique pour encadrer la population canadiennefrançaise et promouvoir son propre recrutement, a peutêtre plus servi à réaliser ses propres visées en tant que classe dirigeante qu'à assurer la scolarisation de la masse. Quoi qu'il en soit, la question vaut la peine d'être posée.

\section{IV - STructure Sociale}

La société d'Ottawa ne devait pas uniquement ses polarisations sociales à son caractère multiethnique et multiconfessionnel, mais aussi à son intégration dans l'économie forestière de la vallée de l'Outaouais, ainsi qu'à son rôle à peine amorcé de capitale nationale. Tels sont les facteurs qui, en plus des niveaux d'instruction, déterminèrent pour l'essentiel les divisions sociales et la répartition des individus en classes. Il n'est donc pas possible d'analyser les composantes des structures sociales en assumant qu'il existait des frontières étanches entre chacune de ces grandes variables. 
A. LA DYNAMique DE LA CONSTITUTION DU REVENU FAMILIAL

Parmi les individus ayant déclaré des occupations, à part celle des épouses confinées au foyer, il existait une dynamique qui allait du chef de la maisonnée jusqu'aux épouses avec emploi rémunéré, aux enfants adultes avec emploi salarié et aux étrangers ayant un emploi salarié et payant une pension au chef de la maisonnée.

TABLEAU 23

Structure des occupations parmi les chefs de maisonnée par groupe ethnique à Ottawa en 1871 .

\begin{tabular}{|c|c|c|c|c|c|}
\hline & Écossais, & & dais & Canadiens & Total \\
\hline & Anglais, & protestants & catholiques & français & \\
\hline Professions & $t$ affaires & & & & \\
\hline effectifs & 468 & 188 & 163 & 198 & 1017 \\
\hline$\%$ & 40,6 & 33,4 & 19,9 & 15,0 & 26,4 \\
\hline Ouvriers qu & & & & & \\
\hline effectifs & 475 & 219 & 200 & 463 & 1357 \\
\hline$\%$ & 41,2 & 39,0 & 24,5 & 35,1 & 35,2 \\
\hline Ouvriers n & & & & & \\
\hline effectifs & 147 & 120 & 379 & 626 & 1272 \\
\hline$\%$ & 12,8 & 21,3 & 46,4 & 47,5 & 33,0 \\
\hline $\begin{array}{l}\text { Personnes } \\
\text { veuves }\end{array}$ & ation déc & & & & \\
\hline effectifs & 50 & 32 & 69 & 28 & 169 \\
\hline$\%$ & 4,3 & 5,7 & 8,4 & 2,1 & 4,6 \\
\hline veufs & & & & & \\
\hline effectifs & 12 & 3 & 6 & 4 & 25 \\
\hline$\%$ & 1,0 & 0,5 & 0,7 & 0,3 & 0,6 \\
\hline Total & & & & & \\
\hline effectifs & 1152 & 562 & 817 & 1319 & 3850 \\
\hline$\%$ & 100 & 99,9 & 99,9 & 100 & 99,8 \\
\hline
\end{tabular}

Source: APC, Recensement nominatif d'Ottawa de 1871, bobines 10013 , 10014 et 10015.

Ces chiffres et ceux du tableau 19 indiquent que la société d'Ottawa se départageait en quatre groupes inégaux en ce qui concerne la richesse, le niveau d'instruction, le prestige et le pouvoir. D'abord, au haut de l'échelle, 
logeaient les Écossais, les Anglais et les Allemands, dont les effectifs étaient fortement surreprésentés dans les professions libérales, les affaires et les ouvriers qualifiés. Les Irlandais protestants se situaient nettement au niveau intermédiaire, tandis que les Canadiens français et les Irlandais catholiques, loin derrière les autres, se disputaient les troisième et quatrième positions. Il est vrai que les Irlandais catholiques étaient plus présents dans les milieux d'affaires et les professions libérales, mais les Canadiens français l'emportaient sur eux parmi les ouvriers qualifiés et non qualifiés.

Parmi les chefs de maisonnée, les femmes, au nombre de 418 (11\%), étaient les personnes les moins fortunées. Dans ce groupe, il y avait 386 veuves inégalement réparties entre les groupes ethniques. Leur pourcentage respectif relativement à l'ensemble des chefs de maisonnée étaient de $7,2 \%$ pour les Écossaises, les Anglaises et les Allemandes, de $16,5 \%$ pour les Irlandaises catholiques, de $13 \%$ pour les Irlandaises protestantes et de $7,4 \%$ pour les Canadiennes françaises. La surreprésentation des Irlandaises, surtout des Irlandaises catholiques, provenait peut-être davantage des séquelles des épidémies de choléra des années 1832,1834 et 1847 que de toute autre cause. Plus de $70 \%$ d'entre elles avaient des enfants, fort souvent trop jeunes pour avoir un emploi. Celles qui n'étaient pas entourées d'enfants adultes, mariés ou non, avaient dû ou pu trouver un emploi ${ }^{39}$. Cette nécessité d'un emploi existait aussi parmi les femmes célibataires. Le nombre de veuves dans cette situation se chiffrait à 207 et celui des célibataires à 32 . Certaines se disaient rentières (un nombre surprenant surtout parmi les Irlandaises catholiques), hôtelières, épicières, institutrices, infirmières, alors que d'autres gardaient des pensionnaires. Le métier de couturière s'accordait bien à

${ }^{39}$ Bettina Bradbury, Familles ouvrières à Montréal. Âge, genre et survie quotidienne pendant la phase d'industrialisation, Montréal, Boréal, 1995, p. 262-275. 
leur situation, puisque 39 d'entre elles s'y adonnaient. Encore là, une assez grande inégalité régnait parmi les groupes ethniques. Celles qui se disaient laveuses, domestiques et journalières représentaient $17 \%$ des femmes salariées chez les Écossaises, les Anglaises et les Allemandes, $46 \%$ chez les Canadiennes françaises, $42 \%$ chez les Irlandaises catholiques et $37 \%$ chez les Irlandaises protestantes. Il est évident que les veuves les plus vulnérables se recrutaient parmi les 179 veuves qui n'avaient pas déclaré d'occupation au recensement et qui, en charge d'enfants en bas âge, ne pouvaient compter sur l'apport financier de membres de la famille.

Dans tous les groupes ethniques, particulièrement chez les travailleurs non qualifiés et chez les femmes en charge de maisonnée, le besoin d'un revenu d'appoint s'imposait. Ce besoin était d'autant plus ressenti chez les Irlandais catholiques et les Canadiens français que $46 \%$ et $47 \%$ respectivement de leurs chefs de maisonnée contre $16 \%$ chez les autres appartenaient à ce groupe. Cette contribution aurait pu venir du travail rémunéré des épouses. Mais cette solution n'avait prévalu qu'en dernier ressort. Aussi seulement 40 familles, dont 26 canadiennes-françaises, y avaient-elles eu recours. Pas étonnant que l'immense majorité des emplois qu'elles avaient obtenus aient été ceux de couturières, de laveuses, de blanchisseuses et de journalières. Parmi les Canadiennes françaises, les couturières et les blanchisseuses étaient au nombre de 23. Notons que, si modeste fut-il, l'apport financier des enfants adultes avec emploi salarié, qu'ils aient vécu à la maison ou à l'extérieur, était celui sur lequel les parents des milieux populaires comptaient davantage. 
DiSPARITÉS SOCIO-ÉCONOMIQUES ET CULTURELLES À OTTAWA EN 1871

TABLEAU 24

Répartition par occupation des épouses, des enfants adultes vivant à la maison, ayant déclaré une occupation, et des domestiques selon leur origine ethnique à Ottawa en 1871 .

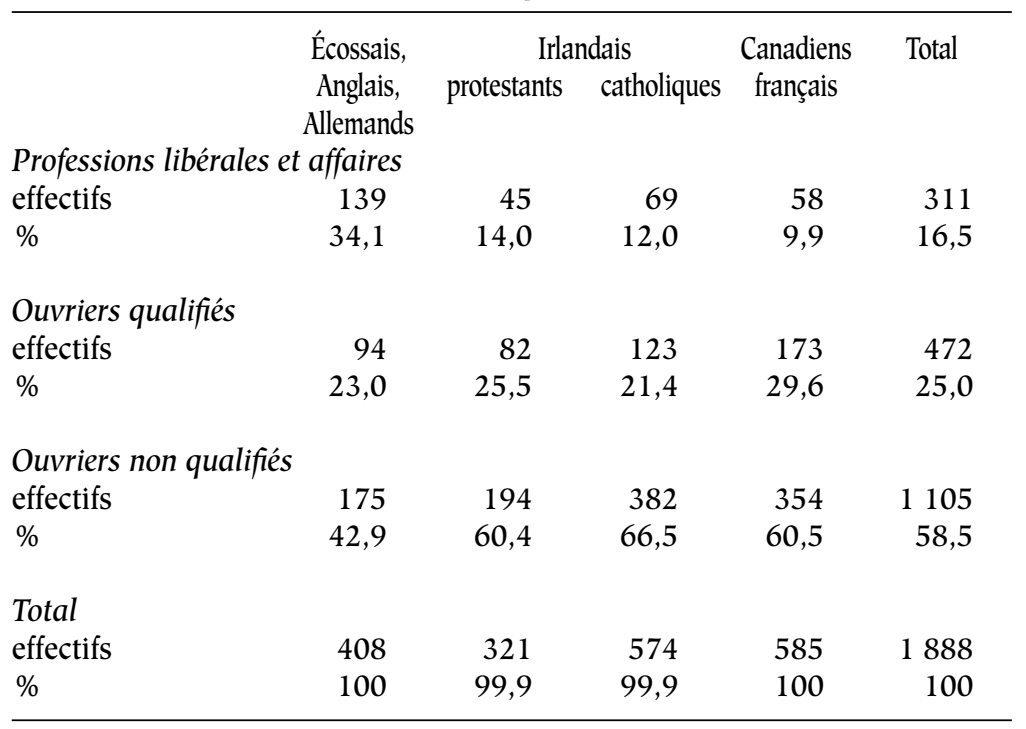

Source: APC, Recensement nominatif d'Ottawa de 1871, bobines 10013 , 10014 et 10015 .

Dans les circonstances, ce rôle de suppléance avait été assumé en grande partie par les enfants adultes, non mariés, vivant ou non à la maison, mais ayant un emploi. Comme les perspectives de promotion sociale venant de l'intérieur n'étaient pas très brillantes, cette responsabilité retomba principalement sur la modeste contribution des travailleurs non qualifiés, qui constituaient $58 \%$ des individus. Néanmoins, entre, d'une part, les Écossais, les Anglais et les Allemands, et, d'autre part, les Irlandais et les Canadiens français, il existait une grande différence, puisque les ouvriers non qualifiés accaparaient $43 \%$ des individus chez les premiers et $63 \%$ chez les seconds. Notons cependant que les Canadiens français auraient été encore plus nombreux dans cette catégorie de travailleurs avec emploi si le facteur linguistique n'avait pas tellement favorisé leurs concurrents irlandais catholiques sur le marché 
du travail. Ceci dit, c'était le grand nombre de servantes, 729 sur 1888 individus, soit 39\%, et, par conséquent, le grand nombre de femmes, qui expliquent les taux tellement élevés d'ouvriers non qualifiés dans tous les groupes ethniques.

\section{TABLEAU 25}

Emplois féminins rémunérés parmi les épouses, les enfants adultes et les domestiques à Ottawa en 1871.

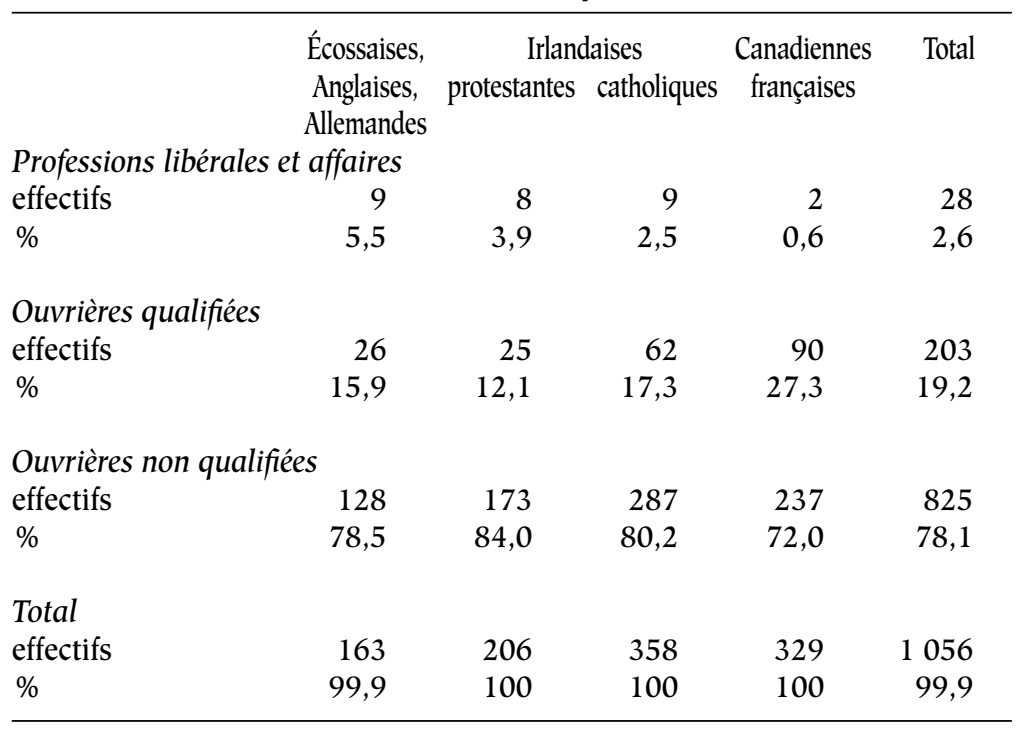

Source: APC, Recensement nominatif d'Ottawa de 1871, bobines 10013 , 10014 et 10015.

Ainsi, les femmes représentaient $56 \%$ ( 1056 personnes dans le tableau 25) des travailleurs dans ce groupe d'individus ( 1888 dans tableau 24) qui constituait à la fois la relève sociale et la source principale du revenu d'appoint indispensable aux familles les plus pauvres. Leur concentration parmi les ouvriers non qualifiés se situait à près de $80 \%$, alors que celle des garçons n'était que de $39 \%$, c'està-dire seulement $4 \%$ de plus que les chefs de maisonnée. 
Enfin, il y avait le groupe, très hétérogène sur le plan ethnique et autrement, que nous avons appelé les étrangers et qui résidaient dans les maisonnées ordinaires, les maisons de pension, les petits hôtels et les institutions religieuses. La grande majorité de ces individus y payaient pension, contribuant ainsi au revenu des familles où ils résidaient. La plupart d'entre eux avaient, d'une façon ou d'une autre, déclaré des occupations. Dans les institutions religieuses, à peu près tout le monde était mis à contribution : les uns prêchaient, enseignaient, soignaient les malades, s'occupaient des pauvres, fabriquaient des choses pour le marché, alors que d'autres, à un niveau plus élevé, géraient et dirigeaient. Les revenus des oblats, des sœurs grises, des frères des Écoles chrétiennes et des dames de la Congrégation provenaient de sources variées: les dîmes ou leurs équivalents, les quêtes, les honoraires, les frais de scolarité et les dons. À ce sujet, Élizabeth Bruyère, supérieure des sœurs grises, écrivait: "les ressources consistent dans notre travail manuel et dans les rétributions des enfants qui fréquentent nos écoles, qui pour la plupart sont pauvres et ne payent pas $[\ldots]^{40} »$.

${ }^{40}$ Cité dans Robert Choquette, op. cit., p. 165. 
TABLEAU 26

Occupations des étrangers en résidence dans les maisonnées privées et les institutions, ayant déclaré une occupation à Ottawa en 1871.

\begin{tabular}{lcccc}
\hline & $\begin{array}{c}\text { Écossais, } \\
\text { Anglais, } \\
\text { Allemands }\end{array}$ & Irlandais & $\begin{array}{c}\text { Canadiens } \\
\text { français }\end{array}$ & Total \\
& 22 & 13 & 167 & 202 \\
$\begin{array}{l}\text { Professions libérales } \\
\text { effectifs } \\
\%\end{array}$ & 8,2 & 6,1 & 52,5 & 25,3 \\
$\begin{array}{l}\text { Affaires } \\
\text { effectifs } \\
\%\end{array}$ & 74 & 63 & 23 & 160 \\
$\begin{array}{l}\text { Ouvriers qualifiés } \\
\text { effectifs }\end{array}$ & 27,7 & 29,7 & 7,2 & 20,1 \\
$\%$ & 134 & 107 & 78 & 319 \\
$\begin{array}{l}\text { Ouvriers non qualifiés } \\
\text { effectifs } \\
\%\end{array}$ & 50,2 & 50,5 & 24,5 & 40,0 \\
$\begin{array}{l}\text { Total } \\
\text { effectifs }\end{array}$ & 37 & 29 & 50 & 116 \\
$\%$ & 13,8 & 13,7 & 15,7 & 14,5 \\
\hline
\end{tabular}

Source: APC, Recensement nominatif d'Ottawa de 1871, bobines 10013 , 10014 et 10015 .

C'est sans doute ici que les chiffres illustrent le mieux le contraste entre les Canadiens français et les autres. En effet, parmi les étrangers, la moitié des anglophones était concentrée parmi les ouvriers qualifiés, alors que plus de la moitié des Canadiens français l'était dans les professions libérales. La faiblesse de la classe d'affaires canadienne-française était non moins éclatante que sa présence dominante parmi les membres du corps ecclésiastique catholique masculin et féminin. Le poids relatif des ouvriers non qualifiés était ici sensiblement égal dans tous les groupes ethniques. Tout cela confirme le fait que le pouvoir canadien-français, dans la mesure où il pouvait s'affirmer à l'extérieur, s'exprimait en dehors de la sphère économique et, hors du milieu canadien-français, surtout dans les coulisses politiques. 
Le lecteur sera aussi frappé par le fait que, dans cette catégorie sociale, non seulement les femmes représentaient $27 \%$ des effectifs, mais elles y composaient $75 \%$ de ceux qui se rattachaient aux professions libérales. Celles-ci étaient dominées numériquement par les religieuses qui, tout en participant à l'expansion du pouvoir clérical dans la société canadienne-française, travaillaient surtout à soigner les malades, à aider les femmes dans le besoin et à instruire les filles.

\section{TABLEAU 27}

Occupations des femmes dans la catégorie "Étrangers» à Ottawa en 1871.

\begin{tabular}{lcccc}
\hline & $\begin{array}{c}\text { Écossaises, } \\
\text { Anglaises, } \\
\text { Allemandes }\end{array}$ & Irlandaises & $\begin{array}{c}\text { Canadiennes } \\
\text { françaises }\end{array}$ & Total \\
Professions libérales & 2 & 4 & 126 & 132 \\
effectifs & & & & \\
$\%$ & 7,1 & 16,7 & 75,4 & 60,3 \\
$\begin{array}{l}\text { Affaires } \\
\text { effectifs }\end{array}$ & & & & \\
$\%$ & 1 & 3 & 1 & 5 \\
$\begin{array}{l}\text { Ouvrières qualifiées } \\
\text { effectifs }\end{array}$ & 3,6 & 12,5 & 0,6 & 2,3 \\
$\%$ & 22 & 16 & 20 & 58 \\
$\begin{array}{l}\text { Ouvrières non qualifiées } \\
\text { effectifs } \\
\%\end{array}$ & 78,6 & 66,7 & 12,0 & 26,5 \\
$\begin{array}{l}\text { Total } \\
\text { effectifs } \\
\%\end{array}$ & 3 & 1 & & \\
\hline
\end{tabular}

Source: APC, Recensement nominatif d'Ottawa de 1871, bobines 10013 , 10014 et 10015 .

En somme, le niveau de richesse des familles reflétait à la base celui des chefs de maisonnée. Dans tous les groupes ethniques, il existait une hiérarchie des revenus qui différait d'un groupe à l'autre et variait à l'intérieur de chacun 
d'eux selon la nature des occupations. Les plus défavorisés étaient les Canadiens français et les Irlandais catholiques, tous deux fortement surreprésentés dans la classe ouvrière, particulièrement parmi les travailleurs non qualifiés et les veuves n'ayant pas déclaré d'occupation. Naturellement, les familles les plus pauvres avaient besoin d'un revenu d'appoint qui ne pouvait venir que des épouses, des enfants adultes vivant à la maison et travaillant à l'extérieur, ou bien, des étrangers payant pension. Le plus souvent, bien qu'essentiel, cet apport était modeste. Il l'était d'autant plus que les travailleurs en question étaient des femmes et, en majorité des servantes. Les religieuses étaient sans doute entourées de prestige, mais, individuellement, leurs activités n'étaient pas parmi les mieux rémunérées, en tout cas peu susceptibles d'alléger les effets de la pauvreté. Si nous savions jusqu'à quel point le facteur linguistique a pu jouer contre certaines catégories de travailleurs canadiensfrançais, notamment les femmes, sur le marché du travail, il serait peut-être possible de déterminer catégoriquement qui des Irlandais catholiques ou des Canadiens français étaient les plus défavorisés.

\section{B. LES CLASSES DIRIGEANTES}

Dans cette société, la classe dirigeante économique se recrutait principalement parmi les Écossais, les Anglais et les Irlandais protestants. Certains avaient transité par les États-Unis, mais la grande majorité était née dans les îles Britanniques. Comme la ville devait d'abord son développement à l'industrie forestière et à la demande croissante de bois d'œuvre sur le marché américain, les entrepreneurs forestiers jouèrent un rôle capital, non seulement sur le plan économique, mais aussi, directement ou indirectement, au niveau social et politique. Seulement 3,4\% des entreprises étaient entre leurs mains, mais elles réunissaient $45 \%$ de la main-d'œuvre industrielle et la valeur de leurs produits s'établissait à 1697000 \$, soit $40 \%$ de la production totale. 
La plupart de ces hommes d'affaires avaient de grandes réserves forestières dans l'hinterland où ils se ravitaillaient eux-mêmes en bois. De plus, nombre d'entrepreneurs forestiers habitant Ottawa, tels Allan Gilmour, Edward McGillivray et Joseph Aumont, dont les activités n'apparaissaient pas au recensement, opéraient seulement dans la vallée ${ }^{41}$. D'autres entreprises importantes, plus ou moins indépendantes de l'industrie forestière, existaient. Ainsi Thomas MacKay convertissait 186347 boisseaux de céréales en farine, pour une valeur de 194854 \$, pendant que les trois imprimeries de la ville donnaient du travail à 264 personnes pour des productions estimées à $233897 \$$. Et cela, sans compter les banques et les chemins de fer.

À côté de ces douze entreprises, toutes possédées par des protestants, employant 1652 personnes, dont la valeur de la production se chiffrait à 2125751 \$, foisonnaient les entreprises de moindre taille dispersées dans tous les secteurs d'activité.

TABLEAU 28

Entreprises industrielles, main-d'œuvre

et valeur de la production à Ottawa en 1871 .

\begin{tabular}{lrcrrrr}
\hline & \multicolumn{3}{c}{ canadiennes-françaises } & \multicolumn{3}{c}{ anglophones } \\
Valeur (\$) & nombre & ouvriers & valeur (\$) & nombre & ouvriers & valeur (\$) \\
moins 10 000 & 45 & 129 & 97905 & 109 & 329 & 450496 \\
$\%$ & 81,8 & 51,2 & 30,2 & 60,9 & 11,7 & 11,6 \\
10 000-49 999 & 10 & 123 & 226549 & 57 & 848 & 1181130 \\
$\%$ & 18,2 & 48,8 & 69,8 & 31,8 & 30,2 & 30,4 \\
50 000-99 999 & 0 & 0 & 0 & 4 & 198 & 244400 \\
$\%$ & & & & 2,2 & 7,0 & 6,3 \\
100 000 et plus & 0 & 0 & 0 & 9 & 1432 & 2005065 \\
$\%$ & & & & 5,0 & 51,0 & 51,7 \\
Total & 55 & 252 & 324454 & 179 & 2807 & 3881231 \\
$\%$ & 100 & 100 & 100 & 99,9 & 99,9 & 100 \\
\hline
\end{tabular}

Source: APC, Recensement nominatif d'Ottawa de 1871, bobines 10013 , 10014 et 10015 .

${ }^{41}$ Louis Gentilcore and Grant Head, Ontario History in Maps, Toronto, Ontario Historical Studies, UTP, 1984, p. 138 pour une carte des concessions forestières. 
Les Canadiens français ne possédaient que $23,5 \%$ des entreprises, n'engageaient que $8,2 \%$ des ouvriers et la valeur de leur production ne représentait que $7,7 \%$ de l'ensemble, ce qui veut dire que les anglophones dominaient dans les activités industrielles. Dans l'ensemble de la maind'œuvre de ces entreprises, la part des femmes se chiffrait à $16 \%$, dont $96 \%$ dans les domaines associés au vêtement.

Bien plus, la croissance en nombre et en volume des entreprises liées à l'exploitation de la forêt, ainsi que l'émergence du rôle d'Ottawa en tant que capitale nationale, avaient avec le temps donné un élan à la valeur de la propriété foncière sur le territoire de la ville. Parmi les grands propriétaires originaux, Louis-Théodore Besserer n'était plus et Nicolas Sparks ne possédait que 1000 acres de terre. Le seul domaine qui semblait intact était celui de feu le colonel By avec ses 3380 acres. Mais, depuis 1830, la liste s'était allongée et diversifiée. Le nombre de ceux qui avaient accumulé 300 acres et plus atteignait maintenant 63 individus qui, en moyenne, possédaient 1181 acres.

Dans ce groupe, les hommes d'affaires étaient les plus nombreux (48\%), mais chacun ne possédait que 975 acres en moyenne. Néanmoins, James Skead, qui se disait marchand de bois, s'était approprié 5000 acres de terre sur lesquelles on dénombrait 233 lots de ville, 12 maisons, 17 granges et étables, 233 wagons, 75 voitures et 23 charrues. L'Écossais Thomas McKay, propriétaire du plus gros moulin à farine de la ville, n'était pas en reste avec ses 3100 acres. À leur suite, venaient les politiciens et les hauts fonctionnaires au nombre de 12 et possédant 2296 acres en moyenne. William Powell, le shérif de la ville, était bon premier avec ses 6300 acres, alors que J. King, le directeur des pénitentiers, était deuxième avec 5000 acres. Georges-Étienne Cartier se classait troisième avec 3360 acres $^{42}$. Presque en fin de liste,

${ }^{42}$ Cet investissement n'est pas mentionné dans la liste des activités foncières de Cartier dressée par Brian Young, Georges-Étienne Cartier, Montreal Bourgeois, Kingston and Montréal, M-QUP, 1981, p. 136-143. 
après Jean-Charles Taché avec 2235 acres, les noms de Samuel Léonard Tilley avec 1200 acres et de Sir Francis Hincks avec 1000 acres, apparaissaient. Les membres des professions libérales figuraient en bonne place parmi ces privilégiés, puisque leurs avoirs moyens se chiffraient à 1337 acres. En fin de liste une douzaine d'individus, aux occupations variées, possédaient 611 acres en moyenne. Tous ces gens bien assis financièrement, influents socialement et bien en place sur le plan politique étaient Anglais, Irlandais, Écossais dans une proportion de $89 \%$ et protestants à $87 \%$. Les six Canadiens français étaient catholiques ainsi que deux anglophones.

Ici, nous pouvons nous demander dans quelle mesure la fonction publique fédérale et municipale, prise dans son ensemble, reflétait le profil de la classe dirigeante au point de ne servir qu'à étendre son emprise au niveau politique et administratif. En 1867, selon John Taylor, «Numbers of francophones in the C[ivil] S[ervice] correspond to their numbers in the population generally, and they were distributed reasonably equitably through all ranks, protected, it seems, by political patronage ${ }^{43} »$. Disons d'abord que le corps des serviteurs de l'État, qu'il s'agisse des ministres ou de ceux qui dépendaient d'eux, était un organisme hiérarchisé qui, en général, faisait appel à des personnes beaucoup plus alphabétisées et qualifiées que la masse. Le niveau des salaires, excepté celui des plus qualifiés, était modeste, mais constant. À la maison, les ministres pouvaient avoir à leur service des «butlers» et des domestiques, et les autres, tout dépendant de leur rang, des servantes. L'âge moyen de ces fonctionnaires égalait à peu près celui des chefs de maisonnée de la ville: 42,8 ans contre 41,3 . La grande majorité d'entre eux était née à l'extérieur de la province: les Écossais, les Anglais et les Allemands dans une proportion de $67,2 \%$, les Irlandais

${ }^{43}$ Taylor, op. cit., p. 120. 
de $72 \%$ et les Canadiens français de $94,3 \%$. Cependant, à cet égard, il y avait une différence significative entre eux et les chefs de maisonnée, dont les pourcentages respectifs étaient de $83,2 \%$ pour les premiers, de $84,4 \%$ pour les Irlandais et de $93,2 \%$ pour les Canadiens français, ce qui s'explique en partie par le fait que les anglophones avaient précédé les Canadiens français dans la province. Il ne faut pas, non plus, oublier que, depuis le déménagement de la capitale nationale à Ottawa en 1857 , les ministres avaient recruté du personnel dans leurs provinces respectives. Ainsi, $11,4 \%$ des anglophones et $92,2 \%$ des Canadiens français étaient nés au Québec, alors que 6,5\% des anglophones étaient nés dans les provinces atlantiques, où Samuel Tilley et Charles Tupper avaient la haute main.

En 1871, le service civil était dominé par les Écossais, les Anglais et les Allemands; ensemble, ils fournissaient $51 \%$ des serviteurs du gouvernement et de la ville, même s'ils ne constituaient que $29 \%$ de la population. Les Irlandais protestants étaient aussi surreprésentés, mais à un moindre degré qu'eux; ils formaient $14 \%$ de la population de la ville mais $20 \%$ de la fonction publique. Les deux groupes infériorisés étaient les Canadiens français: $37 \%$ dans la population et $21 \%$ dans le service civil, et surtout les Irlandais catholiques: $23 \%$ dans la ville et $9 \%$ dans les services publics. Les catholiques qui formaient $59 \%$ de la population de la ville, étaient sous-représentés, détenant seulement $31 \%$ de ces emplois.

Étant donné la grande faiblesse des Canadiens français dans les milieux d'affaires, leur présence, plus importante dans ces emplois qu'on s'y attendrait, témoignait de l'existence parmi eux d'une élite laïque qui, de plusieurs façons, faisait le pont entre le pouvoir politique, l'administration publique et le monde ecclésiastique. À l'origine de cette situation, il y avait d'abord eu l'énorme prestige et pouvoir dont avait joui Georges-Étienne Cartier. Des individus, tels Étienne Parent, Antoine Gérin-Lajoie, François-Xavier Prieur, 
Robert Shore Bouchette, Stanislas Drapeau et Joseph-Charles Taché, attirés à Ottawa, étaient des personnages au milieu de la cinquantaine et pouvaient exercer une certaine influence. Assurant leur relève se trouvaient environ 45 individus dans la trentaine. C'est parmi eux que se recrutaient surtout les membres actifs de l'Institut canadienfrançais d'Ottawa, équivalent de l'Irish Literary Association. Il est difficile de dire quelle était la nature de leurs rapports avec les Canadiens français. Il est certain, cependant, que la plupart d'entre eux étaient au mieux avec le clergé qui, grâce au réseau d'institutions qu'il avait créé, était sans conteste le principal chef de file des Canadiens français dans la ville et la région.

Entre le clergé catholique à dominance canadiennefrançaise et les classes dirigeantes catholiques anglophones, les rapports étaient tendus. En effet, aux yeux des Irlandais catholiques, le diocèse d'Ottawa paraissait maintenant avoir été taillé d'autorité à la mesure de la présence canadienne-française des deux côtés de la vallée de l'Outaouais. Ce caractère avait d'ailleurs été renforcé par la grande pénurie de prêtres d'origine irlandaise disposés à servir dans un contexte où, selon l'expression de $\mathrm{M}^{\mathrm{gr}}$ Guigues, "on est exposé à ne voir louer que ce qui est pratiqué dans une patrie différente" au point qu'il fallait avoir «la vertu d'un père Molloy» pour tenir le coup ${ }^{44}$. Comme la population catholique était multiethnique et que, même dans les missions indigènes et "canadiennes", il fallait, fort souvent, négocier avec les patrons angloprotestants pour traiter avec leurs employés, la politique de bilinguisme adoptée par l'évêque à propos du personnel clérical avait été maintenue. Pourtant, elle rencontrait bien des résistances, surtout de la part des prêtres irlandais n'ayant pas étudié au Québec. Cette politique paraissait si justifiable aux yeux de l'évêque qu'en 1857, il avait déclaré:

${ }^{44}$ Cité dans Robert Choquette, op. cit., p. 151. 
on exagère d'ailleurs la difficulté de desservir une congrégation irlandaise. Un prêtre français qui a un peu l'habitude de l'anglais peut la desservir et le fait souvent avec plus de succès qu'un prêtre irlandais ${ }^{45}$.

Pourtant, en tant qu'oblat qui voyait le rayonnement de son ordre à l'échelle de l'Amérique, il avait aussi prétendu que :

le français n'[était] pas la langue destinée à promouvoir les intérêts catholiques. Car son action diminue chaque jour. L'Amérique appartient à la langue anglaise [...]. Les Anglais et surtout les Irlandais [étaient] donc les peuples qui [devaient] propager, soutenir et peut-être [...] faire dominer le catholicisme en Amérique ${ }^{46}$.

N'était-ce pas là l'argument soutenu par les classes dirigeantes irlandaises catholiques sur la place qui leur revenait dans la hiérarchie catholique en Ontario et même dans le diocèse d'Ottawa? Les Irlandais catholiques étaient sans doute mieux situés que les Canadiens français dans les milieux d'affaires et, en dehors des villes dans les activités agricoles, mais ils leur étaient inférieurs dans la fonction publique et dans la hiérarchie cléricale. C'est pourquoi nous ne saurions confondre leur rang dans la structure sociale avec celle des Irlandais protestants qui se tenaient plus près des détenteurs de la richesse et du pouvoir.

\section{UNE SECTION DU PROLÉTARIAT: LES JOURNALIERS, LES HOMMES DE CHANTIER ET LES VOYAGEURS}

Dans le passé, bien des employeurs anglo-protestants avaient eu tendance à dénigrer les travailleurs irlandais catholiques en les qualifiant d'insatisfaits, de querelleurs, d'ivrognes et d'ouvriers peu profitables. Cela ne les avait pas empêchés de les engager. C'est peut-être en raison de leur sens de la revendication et de leurs antécédents syndicaux que certains Irlandais, tel Daniel Donoghue, se firent au cours des années 1860 les créateurs de syndicats parmi

${ }^{45}$ Ibid.

${ }^{46}$ Ibid. 
les artisans et les typographes ${ }^{47}$. Au contraire, aux yeux des entrepreneurs opérant dans la vallée, les Canadiens français semblaient dociles, plus compétents et de bonne humeur. Le clergé était d'accord avec eux sur ce point, ce qui, toutefois, ne l'empêchait pas de dénoncer le climat d'immoralité qui régnait parmi les hommes de chantier. Dans ces chantiers, racontait l'abbé Joseph Désautels, «les crimes les plus honteux» sont commis, on y entend «les blasphèmes les plus horribles ${ }^{48} »$. Et l'abbé F. Jeannotte de renchérir: «les terribles blasphèmes [...] et le vice que saint Paul défend de nommer [...] [et] l'ivrognerie ${ }^{49} »$. Pour le clergé, ces jeunes Canadiens français venus de partout, abandonnés à eux-mêmes, étaient des âmes en péril, qu'il fallait prendre en charge sur place ou à l'embouchure des rivières, à leur descente des chantiers dans le cadre des «missions canadiennes». Si d'aventure, disait-il, ils aboutissaient à Ottawa, ils devenaient alors incontrôlables: «à Bytown, disait le père Eusèbe Durocher, ils ont des connaissances qui sont bien loin d'être bonnes, ils n'ont pas vu le monde depuis longtemps $\mathrm{s}^{50}$ ». En 1843, l'abbé Hippolyte Moreau, missionnaire chez les Amérindiens, en route de Montréal vers l'Outaouais supérieur, avait envoyé l'équipage de son canot camper à Hull ${ }^{51}$, de crainte que ses membres ne se laissent attirer par les délices d'Ottawa.

\footnotetext{
${ }^{47}$ Taylor, op. cit., p. 86.

${ }^{48}$ Cité dans Choquette, op. cit., p. 157.

${ }^{49}$ Id., p. 159.

${ }^{50}$ Ibid.

${ }^{51}$ Fernand Ouellet et René Dionne, Journal du père Dominique du Ranquet..., p. 83 .
} 
TABLEAU 29

Voyageurs, hommes de chantiers, journaliers et charretiers

à Ottawa en 1871.

\begin{tabular}{lrrrrrr}
\hline & \multicolumn{2}{c}{ protestants } & \multicolumn{2}{c}{ catholiques } & \multicolumn{2}{c}{ total } \\
& nombre & $\%$ & nombre & $\%$ & nombre & $\%$ \\
Écossais & 35 & 15,8 & 4 & 0,4 & 39 & 3,1 \\
Anglais & 74 & 33,3 & 9 & 0,9 & 83 & 6,5 \\
Allemands & 2 & 0,9 & 3 & 0,2 & 5 & 0,4 \\
Irlandais & 109 & 49,1 & 375 & 35,9 & 484 & 38,2 \\
Anglophones & 220 & 99,1 & 391 & 37,4 & 611 & 48,2 \\
Canadiens français & 2 & 0,9 & 654 & 62,6 & 656 & 51,8 \\
Total & 222 & 100 & 1045 & 100 & 1267 & 100 \\
\hline
\end{tabular}

Source: APC, Recensement nominatif d'Ottawa de 1871, bobines 10013 , 10014 et 10015 .

En vérité, c'était par milliers d'individus que se comptait cette main-d'œuvre forestière qui se recrutait principalement dans les paroisses rurales de la vallée de l'Outaouais des deux côtés de la rivière, dans celles de la région de Montréal et dans la ville d'Ottawa. Pourtant, parmi ceux qui étaient parvenus à la ville pour célébrer le retour des chantiers, il en était plusieurs qui avaient décidé de s'y établir pour de bon. Dans le recensement de 1871, certains d'entre eux se déclaraient "homme de chantier», mais la grande majorité des autres se qualifiait plutôt, comme autrefois dans la traite des pelleteries, de "voyageur».

Dans ces emplois en dehors de la ville, les Canadiens français d'Ottawa étaient nombreux: 176 au total. Presque tous se disaient « voyageurs». Ils étaient âgés d'environ 35 ans, résidaient dans la province depuis une dizaine d'années et $81 \%$ d'entre eux étaient nés au Québec. Les voyageurs nés en Ontario étaient âgés de 23 ans en moyenne, seulement $37 \%$ d'entre eux étaient mariés et ils étaient analphabètes dans une proportion de $55 \%$. Les voyageurs nés au Québec étaient âgés d'environ 37 ans, vivaient en Ontario depuis environ sept années, étaient mariés dans une proportion de $87 \%$ et étaient beaucoup plus analphabètes que les Irlandais travaillant dans les chantiers: 68,5\% 
parmi eux ne savaient pas lire et $78,1 \%$ ne savaient pas écrire.

La grande majorité des travailleurs masculins non qualifiés de la ville, c'est-à-dire les journaliers et les charretiers, étaient Canadiens français. Leurs effectifs se chiffraient à 480, leur âge moyen était de 40 ans, $92 \%$ d'entre eux étaient mariés et ils habitaient la province depuis environ huit ans. Huit pour cent d'entre eux étaient nés en Ontario et leur âge moyen était de 26 ans. Ils constituaient le groupe possédant les plus hauts taux d'analphabétisme de la ville, le pourcentage de ceux qui ne savaient pas lire parmi ceux nés au Québec montait à $81 \%$ et celui de ceux qui ne savaient pas écrire à $87 \%$. Il $y$ avait donc une grande différence entre eux et ceux nés en Ontario dont les taux d'analphabétisme se situaient à $54 \%$ et $57 \%$ respectivement.

Leurs rivaux sur le marché des travailleurs non qualifiés, les Irlandais, étaient à peine présents parmi les «voyageurs" et les hommes de chantier: seulement quatorze catholiques et deux protestants, dix hommes de chantier et six «voyageurs». Ils étaient âgés de 36 ans en moyenne, résidaient en Ontario depuis 16 ans et y étaient nés dans une proportion supérieure à celle des chefs de maisonnée de même origine. Sept sur dix étaient mariés et, excepté les deux protestants qui savaient lire et écrire, ils étaient beaucoup plus analphabètes que les autres Irlandais: $33 \%$ ne savaient lire et $42 \%$ ne savaient écrire.

C'était donc parmi les journaliers et les charretiers que se trouvait le gros des travailleurs non qualifiés masculins irlandais, où ils étaient presque aussi nombreux que les Canadiens français, soit 468 au total incluant 361 catholiques et 107 protestants. Le pourcentage des catholiques nés en Ontario s'établissait à $16 \%$ et celui des protestants à $26 \%$. Celui des catholiques nés dans les îles Britanniques se chiffrait à $79 \%$ et celui des protestants à 
$65 \%$. Catholiques et protestants étaient du même âge: 40 ans en moyenne. Par contre, entre ceux nés en Ontario, au Québec et ailleurs, les différences d'âge étaient considérables : 28,32 et 44 ans en moyenne. La moitié de ceux nés en Ontario étaient mariés, alors que les autres l'étaient dans une proportion de $90 \%$. Les plus alphabétisés étaient nés en Ontario.

\section{Conclusion}

Après 1826, en moins de trois décennies, un site inoccupé sur la rivière Outaouais, nommé Les Chaudières, devint, grâce à la construction du canal Rideau, à l'industrie du bois de sciage et à son choix en 1857 comme capitale des Canadas, la troisième ville de la province. En 1871, la grande majorité des chefs de maisonnée était composée d'immigrants de toutes conditions, nés surtout dans les îles Britanniques et au Québec. Les Écossais, les Anglais et les Allemands étaient arrivés les premiers, les Irlandais à peine quelque temps après eux et les Canadiens français les derniers. En 1871, dans cette ville de plus de 20000 habitants, les Irlandais dominaient numériquement (37,3\% de la population), suivis des Canadiens français $(34,1 \%)$, des Anglais (17,5\%) et des Écossais (10,5\%). Cinquantehuit pour cent de ces individus étaient catholiques, dont $23 \%$ d'Irlandais et $34 \%$ de Canadiens français.

Il est évident que cette population hétérogène ne s'était pas distribuée au hasard sur le territoire urbain. Dès le départ, la distinction entre les riches et les pauvres avait présidé au choix d'un lieu de résidence par les immigrants, surtout par le biais du coût des locations et des propriétés. Ainsi, dans la très grande majorité des cas, les Écossais, les Anglais et les Allemands s'étaient installés à la haute ville ${ }^{52}$. Cette ségrégation reflétait la localisation à la haute ville des principales entreprises, de l'hôtel de ville et des services

${ }^{52}$ Quartiers Wellington, Victoria 1 et Saint-Georges. 
gouvernementaux, sans compter du club de curling, de la patinoire et de la plupart des églises protestantes. Par contre, les édifices de l'Église catholique avaient été érigés à la basse ville ou tout près. Ce n'est pas par hasard si les sœurs grises, les oblats et les frères des Écoles chrétiennes logeaient à la basse ville, alors que les dames de la Congrégation avaient adopté la haute ville. L'Église catholique, la seule grande entreprise canadienne-française, était une Église de pauvres.

Cette répartition territoriale des groupes ethniques riches et pauvres avait de plus pris la forme d'une différence entre protestants et catholiques. Ainsi, à l'exemple des autres protestants, les chefs de maisonnée irlandais s'étaient rassemblés à la haute ville dans une proportion de $62 \%$, alors que seulement le tiers des catholiques de même origine et $6 \%$ des Canadiens français s'y étaient regroupés. Évidemment, la haute ville n'était pas le foyer de l'analphabétisme: un taux de $4 \%$ ici contre un taux de $34 \%$ à la basse ville. Le taux d'analphabétisme des protestants aux deux endroits était de $1,6 \%$ et de $5,3 \%$ respectivement, alors que celui des catholiques était de 3,6\% et de 44,7\%. Même si les Irlandais catholiques de la basse ville étaient trois fois plus analphabètes que les protestants de même origine, la véritable polarisation se situait entre les Canadiens français et les autres. Les Canadiens français ne représentaient que 50\% des chefs de maisonnée de la basse ville, mais $81 \%$ des chefs de maisonnée analphabètes de l'endroit et $77 \%$ de ceux de la ville. Il est vrai que $97 \%$ des ouvriers non qualifiés canadiens-français habitaient à la basse ville. Pourtant les ouvriers non qualifiés anglophones s'y trouvaient aussi dans une proportion de $72 \%$, mais ne comprenaient que $19 \%$ des analphabètes de l'endroit. D'ailleurs, nous pouvons nous demander dans quelle mesure la pauvreté et l'insalubrité de ces quartiers peuvent expliquer les écarts prévalant entre anglophones et Canadiens français au niveau de la mortalité générale et infantile. 
Chaque groupe ethnique paraissait bien ancré dans ses affiliations religieuses traditionnelles. Néanmoins, des chefs de maisonnée écossais, anglais et allemands aux enfants adultes, nous pouvons quand même noter un léger accroissement de la proportion des catholiques : de 7,7\% à 11,1\%. Cette même tendance, à peine perceptible, existait aussi chez les Irlandais : une variation de 60,4\% à 61,6\%. Quant aux Canadiens français, leur pourcentage se situait audessus de 99,3\% dans les deux cas.

C'est certainement dans le domaine de l'alphabétisation et de la fréquentation scolaire que les changements étaient les plus manifestes. Comme les chefs de maisonnée écossais, anglais et allemands étaient à peu près complètement alphabétisés à leur arrivée dans la province, il n'est pas étonnant de constater que les individus nés en Ontario l'aient été moins qu'eux.

Malgré ces changements internes, il se dégage toujours l'impression que ces communautés ethniques demeuraient relativement isolées les unes des autres. Néanmoins, dans la vie réelle, les contacts s'étaient multipliés entre elles jusqu'à un certain point, surtout en milieu anglophone, où régnait une grande diversité dans les adhésions aux Églises. Cette complexité avait sans doute favorisé les mariages exogames qui intégraient des individus d'une autre ethnie ou d'une autre confession religieuse dans les familles.

Richesse, appartenance religieuse, degré d'instruction et moment de l'arrivée étaient donc les facteurs ayant contribué à hiérarchiser ces communautés ethniques. À la racine de ce départage, il y avait le fait que la minorité anglo-protestante plus instruite dominait l'économie et le service civil. En face d'elle, mais, occupant leur propre espace, se trouvaient les majorités irlandaise catholique et canadienne-française qui se disputaient âprement les emplois subalternes dans le monde du travail et le pouvoir à l'intérieur de l'Église catholique. 
En somme, à Ottawa, comme à Hawkesbury et à Alfred, comme aussi en Nouvelle-Angleterre, les Canadiens français venus du Québec rural où ils avaient été, en tout ou en partie, prolétarisés, avaient établi des communautés homogènes de langue française et de religion catholique dans des milieux hétérogènes par l'origine ethnique et la religion. Jusqu'à un certain point, ils y avaient vécu comme si les autres n'avaient pas existé. C'est qu'ils tranchaient en plus sur eux par la rareté de leurs mariages interethniques et interconfessionnels, par leurs taux plus élevés de natalité, de mortalité générale et, surtout infantile, ainsi que par leur analphabétisme.

Vue sous l'angle des rapports privilégiés que les Canadiens français entretenaient avec le clergé catholique qui, à la fois, les servait et les dominait, la ville d'Ottawa était un relais essentiel pour la diffusion dans le diocèse des infrastructures susceptibles de les encadrer et de l'idéologie nationaliste ultramontaine et agriculturiste destinée à les guider dans leur progression territoriale. Entre cette vision cléricale du monde, largement épousée par l'élite laïque et les exigences de la vie réelle en milieu hétérogène, il existait une tension que les Canadiens français ordinaires ont solutionnée en bien des cas à leur façon. Les conflits à l'intérieur même du monde clérical au sujet du bilinguisme, que d'ailleurs, ses membres pratiquaient, liés qu'ils étaient à la nécessité de servir plusieurs communautés ethniques, le démontrent amplement. Tout cela ressemblait au Québec des Cantons de l'Est, de la Gaspésie et de Montréal. 